\title{
M3FT-16OR020202112 - Report on viability of hydrothermal corrosion resistant SiC/SiC Joint development
}

Yutai Katoh

Takaaki Koyanagi James O. Kiggans Jr Kurt A. Terrani

June 30, 2016 


\title{
DOCUMENT AVAILABILITY
}

Reports produced after January 1, 1996, are generally available free via US Department of Energy (DOE) SciTech Connect.

\section{Website http://www.osti.gov/scitech/}

Reports produced before January 1, 1996, may be purchased by members of the public from the following source:

\author{
National Technical Information Service \\ 5285 Port Royal Road \\ Springfield, VA 22161 \\ Telephone 703-605-6000 (1-800-553-6847) \\ TDD 703-487-4639 \\ Fax 703-605-6900 \\ E-mail info@ntis.gov \\ Website http://www.ntis.gov/help/ordermethods.aspx
}

Reports are available to DOE employees, DOE contractors, Energy Technology Data Exchange representatives, and International Nuclear Information System representatives from the following source:

Office of Scientific and Technical Information

PO Box 62

Oak Ridge, TN 37831

Telephone 865-576-8401

Fax 865-576-5728

E-mail reports@osti.gov

Website http://www.osti.gov/contact.html

This report was prepared as an account of work sponsored by an agency of the United States Government. Neither the United States Government nor any agency thereof, nor any of their employees, makes any warranty, express or implied, or assumes any legal liability or responsibility for the accuracy, completeness, or usefulness of any information, apparatus, product, or process disclosed, or represents that its use would not infringe privately owned rights. Reference herein to any specific commercial product, process, or service by trade name, trademark, manufacturer, or otherwise, does not necessarily constitute or imply its endorsement, recommendation, or favoring by the United States Government or any agency thereof. The views and opinions of authors expressed herein do not necessarily state or reflect those of the United States Government or any agency thereof. 
For successful development of silicon carbide (SiC)-based accident tolerant fuel cladding, establishment of hydrothermal corrosion resistant joining technology for the end-plug is recognized as a technical hurdle. The end-plug joint is simultaneously exposed to hot water and neutron irradiation during the normal operation of light water reactors (LWR's). With the objective of selecting suitable joining methods, studies were conducted to determine (1) the hydrothermal corrosion of candidate joints without radiation and (2) neutron irradiation resistance of the joints at an LWR relevant temperature in inert atmosphere. The joining methods investigated include solid state diffusion bonding with titanium and molybdenum interlayers, TiSi-C based reaction sintering, nanophase powder-based transient eutectic phase (TEP) SiC joining, and hybrid processing of polymer pyrolysis and chemical vapor infiltration (CVI). Based on the two studies, summarized in Table I below, it is concluded that the TEP SiC and the hybrid polymer/CVI methods are most promising. The details of the experimental procedure, results, and discussions are found in the attached reports.

Table I Summary of hydrothermal corrosion behavior and irradiation resistance of candidate SiC joints for accident tolerant fuel cladding application.

\begin{tabular}{|l|l|l|l|}
\hline $\begin{array}{l}\text { Joining } \\
\text { Method }\end{array}$ & $\begin{array}{l}\text { Irradiation } \\
\text { Effects }\end{array}$ & $\begin{array}{l}\text { Hydrothermal } \\
\text { Corrosion } \\
\text { (Reducing activity) }\end{array}$ & $\begin{array}{l}\text { Hydrothermal } \\
\text { Corrosion } \\
\text { (Oxidizing activity) }\end{array}$ \\
\hline Ti diffusion & Cracking & Limited recession & Severe recession \\
\hline Mo diffusion & Cracking & Severe recession & Severe recession \\
\hline Ti-Si-C reaction sintering & Cracking & Limited recession & Severe oxidation \\
\hline $\begin{array}{l}\text { Transient eutectic phase } \\
\text { nanopowder sintering SiC }\end{array}$ & Not obvious & Limited recession & Limited recession \\
\hline Hybrid polymer/CVI & No change & Similar to SiC & Similar to SiC \\
\hline \multicolumn{2}{|c|}{ Good performance } & Poor performance & \\
\hline
\end{tabular}

These report documents will be published in periodical scientific journals after the peer-review processes. Release of this report completes the Level 3 Milestone, M3FT-16OR020202112, due June 30, 2016. 
Hydrothermal corrosion of silicon carbide joints without radiation

T. Koyanagi ${ }^{1}$, Y. Katoh ${ }^{1}$, K.A. Terrani ${ }^{1}$, Y.J. Kim², J.O. Kiggans ${ }^{1}$, T. Hinoki ${ }^{3}$

1 Oak Ridge National Laboratory, USA

2 GE Global Research Center, USA

3 Kyoto University, Japan

\begin{abstract}
Hydrothermal corrosion of four types of the silicon carbide $(\mathrm{SiC})$ to $\mathrm{SiC}$ plate joints were investigated under PWR and BWR relevant chemical conditions without irradiation. The joints were formed by metal diffusion bonding using molybdenum or titanium interlayer, reaction sintering using Ti-Si-C system, and $\mathrm{SiC}$ nanopowder sintering. Most of the formed joints withstood the corrosion tests for five weeks. The recession of the $\mathrm{SiC}$ substrates was limited. Based on the recession rate of the bonding layers, it was concluded that all the joints except for the molybdenum diffusion bond are promising under the reducing activity environments. The SiC nanopowder sintered joint was the most corrosion tolerant under the oxidizing activity environment among the four joints.
\end{abstract}

\title{
1. Introduction
}

Silicon carbide (SiC) fiber reinforced $\mathrm{SiC}$ matrix composites are considered as a primary candidate of the accident tolerant fuel cladding of light water reactors (LWRs) because of the outstanding irradiation and oxidation resistances, and low neutron absorption cross section [1, 2]. For the successful development of the $\mathrm{SiC}$ based fuel cladding, joining the cladding to the end-plug is recognized as one of the technological hurdles $[1,2]$. One of the processing difficulties regarding end-cap joining for a long cladding with thin wall thickness is a limitation in applied stress which can be employed during joining. Moreover, the functional requirements of the joint are (1) gas-tightness to retain the fission products inside the cladding, (2) environmental resistance under normal operations: resistances to the hydrothermal corrosion and neutron irradiation, and (3) high-temperature oxidation resistance under a loss of coolant accident condition. 
This paper focuses on hydrothermal corrosion behavior of the SiC joints because of a significant lack of the knowledge. Stempien et al. firstly reported in-pile corrosion behaviors of the SiC plate joints bonded utilizing TiC/SiC tape, calcium aluminate glass, or Ti foil [3]. All types of these joins were completely or partially debonded during the reactor coolant exposure for 44 days and 0.16 displacement per atom (dpa)$\mathrm{SiC}$. Therefore, development of the corrosion tolerant joining method for $\mathrm{SiC}$ is a critical issue. Various joining techniques utilizing different bonding phases are currently available for SiC materials. The candidate joining methods for the LWR cladding end-plug application can be narrowed down based on the irradiation resistance. Katoh et al. demonstrated irradiation tolerant SiC joints fabricated by solid state diffusion bonding, Ti-Si-C reaction sintering based joining, SiC nanopowder sintering based joining, and glass-ceramic joining following neutron irradiation at 500 and $800^{\circ} \mathrm{C}$ up to $5 \mathrm{dpa}$ [4]. Those joining method are potentially useful for the end-plug applications in terms of the radiation resistance.

The solid state diffusion bonding typically utilizes an interlayer of a refractory metal such as titanium, molybdenum, and tungsten [5]. The joining method is well established and the advantage of this joining method is the relatively low joining temperature $\left(\sim 1500^{\circ} \mathrm{C}\right)$, which can avoid a potential damage of the $\mathrm{SiC}$ substrate, especially for $\mathrm{SiC}$ fibers in the composite form. The strengths of Hi Nicalon Type $\mathrm{S}$ and Tyranno SA SiC fibers are known to be degraded by annealing at $\sim 1800^{\circ} \mathrm{C}$ and $\sim 1900^{\circ} \mathrm{C}$, respectively [6]. The drawback is an essential applied stress during joining, which is typically more than a few MPa [5]. The diffusion bonds were typically robust [4, 7]. It may be possible to increase the environmental resistances of this type of the joint by choosing an appropriate interlayer.

The reaction sintering method utilizes Ti-Si-C system provides a bonding layer of $\mathrm{Ti}_{3} \mathrm{SiC}_{2} \mathrm{MAX}$ phase plus secondary phases including SiC, which was originally formed with applied stress of $30 \mathrm{MPa}$ at 1200 $1300^{\circ} \mathrm{C}$ [8]. The pressureless joining method with Ti-Si-C system has been commercially available. The apparent shear strength of the joint was reported to be 100 MPa [4]. The main concern of this type of the bonding layer is poor oxidation resistance of $\mathrm{Ti}_{3} \mathrm{SiC}_{2}$ phase [9], which may be improved by the modification of the composition [10].

The SiC nanopowder sintered joint is formed by sintering mixture of SiC nano-powder and oxide additives such as alumina-yttria [11, 12]. The additives form eutectic liquid during heating, and then the liquid phase promotes sintering SiC powder compact via the solution-precipitation process, which is commonly observed in liquid phase sintering process [13]. In case that the eutectic liquid is a transient phase due to the evaporation, the joining method is specifically referred to as a transient eutectic phase (TEP) sintering bonding $[4,14]$. Although the SiC nanopowder sintering typically requires relatively high processing temperature $\left(\sim 1850^{\circ} \mathrm{C}\right)$ and applied pressure of $\sim 10 \mathrm{MPa}$, this class of SiC joint exhibited the 
highest apparent shear strength among the different types of joints [4]. The key of the development of this joint is a reduction of the joining pressure and controlling the microstructure especially for the secondary phases for the environmental resistances $[15,16]$.

The glass ceramics joining was demonstrated without applying an external stress at relatively low temperature $\left(\sim 1500^{\circ} \mathrm{C}\right)$ for Ca-Al-O system $[4,17]$. The joint strength was typically $\sim 100 \mathrm{MPa}$ in torsion. Because of the discouraging results of the in-pile corrosion experiment on the glass ceramics joint [3], this joint was not investigated in this study.

The promising methods for the clad end-plug application, which are not investigated in this study, are a selected area chemical vapor deposition (CVD) or infiltration (CVI) and a SiC forming polymer-derived joining [18], which can provide pure SiC bonding layer. Hybrid joining technique utilizing these two methods has been employed to the end-plug joining [19].

In this study, the corrosion behaviors of four types of $\mathrm{SiC}$ to $\mathrm{SiC}$ plate joints fabricated via solid state diffusion with $\mathrm{Ti}$ and Mo interlayers, Ti-Si-C reaction sintering, and SiC nanopowder sintering and were investigated under three types of LWR relevant chemical conditions, for up to five weeks for screening purpose. The corrosion experiment was conducted in autoclaves. Based on the corrosion rate and the microstructures of the corroded joints, possible methods to improve the corrosion resistance and future direction of the development of SiC joints for the LWR cladding application were discussed.

\section{Experimental details}

CVD 3C SiC from Dow Chemical Co. (Marlborough, MA) with 99.9995\% purity was used for substrate material for all the joint specimens. The Mo diffusion bond was formed using molybdenum foil ( $25 \mu \mathrm{m}$ thick, 99.95\% pure, Alfa-Aesar, Ward Hill, MA) as a bonding agent. The joining of $\mathrm{SiC} / \mathrm{metal} / \mathrm{SiC}$ sandwiches was accomplished by hot-pressing at $1500^{\circ} \mathrm{C}$, for $1 \mathrm{~h}$, in flowing $\mathrm{Ar}-4 \% \mathrm{H}_{2}$ atmosphere, under a uniaxial pressure of $20 \mathrm{MPa}$. During the hot-pressing, the presence of both hydrogen and titanium powder facilitated effective oxygen gettering. To form Ti diffusion bond, pure titanium foil $(25 \mu \mathrm{m}$ thick, 99.94\% pure, Alfa-Aesar, Ward Hill, MA) was used as the interlayer. The joining of SiC/metal/SiC sandwiches was accomplished by hot-pressing at $1500^{\circ} \mathrm{C}$, for $1 \mathrm{~h}$, in vacuum, under a uniaxial pressure of $17 \mathrm{MPa}$. For Ti-Si-C reaction forming MAX phase bonding, a set of joining agent materials were purchased from Hyper-Therm High Temperature Composites, Inc. (currently Rolls-Royce High Temperature Composites, Inc., Huntington Beach, CA). Ti-Si-C phase-based joints of CVD SiC were produced based on a pressure-less slurry process per the Hyper-Therm formula. Details of the raw 
materials and the process conditions are Hyper-Therm proprietary information. The SiC nanopowder sintered joint was fabricated using slurry of $\mathrm{SiC}$ powder mixture. To prepare the slurry, SiC nano-phase powder (average diameters $\sim 30 \mathrm{~nm}$, Nanomakers, France), and $\mathrm{Al}_{2} \mathrm{O}_{3}$ powder (average diameters $\sim 0.3 \mu \mathrm{m}$, Kojundo Chemical Lab. Co., Ltd., Japan), $\mathrm{Y}_{2} \mathrm{O}_{3}$ powder (average diameters $\sim 0.4 \mu \mathrm{m}$, Kojundo Chemical Lab. Co., Ltd., Japan) were dispersed in ethanol. The total amount of oxide additives was 6 wt\% $\left(\mathrm{Al}_{2} \mathrm{O}_{3}: \mathrm{Y}_{2} \mathrm{O}_{3}=3: 2\right)$. The powders were mixed using milling with zirconia balls. The slurry was sandwiched by CVD SiC plates, and then dried at $\sim 80^{\circ} \mathrm{C}$. After that, the SiC nanopowder sintered joint was formed by hot-pressing at $1850^{\circ} \mathrm{C}$, for $1 \mathrm{~h}$, in an Ar atmosphere, under a pressure of $10 \mathrm{MPa}$. Note that the bonding layer contained the trace of zirconia from the milling media as shown in later. The processing conditions of the joints are summarized in Table 1.

Table 1 Processing conditions of SiC plate joints

\begin{tabular}{|c|c|c|c|c|c|}
\hline $\begin{array}{l}\text { Joining } \\
\text { Method }\end{array}$ & Interlayer & $\begin{array}{l}\text { Joining } \\
\text { Temperature } \\
{\left[{ }^{\circ} \mathrm{C}\right]}\end{array}$ & $\begin{array}{l}\text { Holing Time } \\
\text { at Max. } \\
\text { Temperature } \\
\text { [h] }\end{array}$ & $\begin{array}{l}\text { Joining } \\
\text { Atmosphere }\end{array}$ & $\begin{array}{l}\text { Applied } \\
\text { Stress } \\
{[\mathrm{MPa}]}\end{array}$ \\
\hline Mo diffusion & Mo foil & 1500 & 1 & $\mathrm{Ar}-4 \% \mathrm{H}_{2}$ & 20 \\
\hline Ti diffusion & Ti foil & 1500 & 1 & Vacuum & 17 \\
\hline $\begin{array}{l}\text { Ti-Si-C } \\
\text { reaction sintering }\end{array}$ & Property & Property & Property & Property & $\sim 0$ \\
\hline $\begin{array}{l}\text { SiC nanopowder } \\
\text { sintering }\end{array}$ & $\begin{array}{l}\text { SiC nanopowder, } \\
6 \mathrm{wt} \%\left(\mathrm{Al}_{2} \mathrm{O}_{3}+\mathrm{Y}_{2} \mathrm{O}_{3}\right) \text {, } \\
\mathrm{ZrO}_{2} \text { impurity }\end{array}$ & 1850 & 1 & $\mathrm{Ar}$ & 10 \\
\hline
\end{tabular}

The bonded palates were machined into rectangular $12.0 \times 6.0 \times 1.5 \mathrm{~mm}^{3}$ bars for the Ti and Mo diffusion and MAX phase bonds and into square $6.0 \times 6.0 \times 3.0 \mathrm{~mm}^{3}$ for the SiC nanopowder sintered joint. All samples contained a hole with $2.0 \mathrm{~mm}$ diameter to hang on the specimens in the autoclaves. The location of the bonding layers within the test specimens is shown in Fig. 1. 
(a)

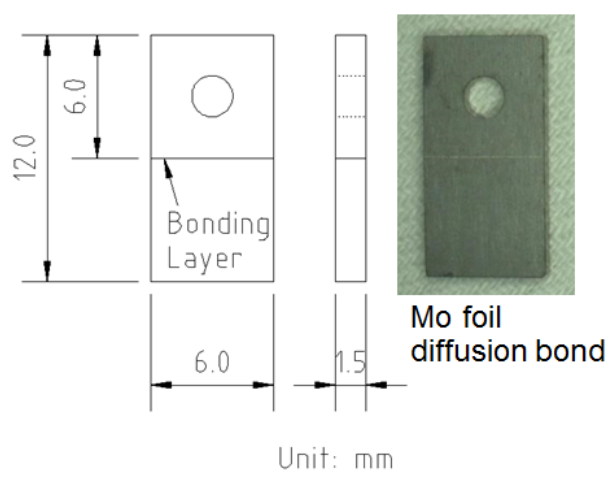

(b)

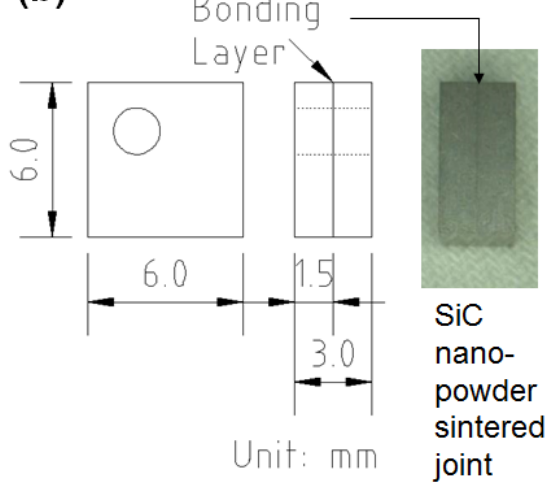

Fig. 1 Dimensions and appearance of SiC joint specimens: (a) rectangular type for Ti and Mo diffusion bond and Ti-Si-C reaction sintered phase joint, (b) square type for SiC nanopowder sintered joint.

The hydrothermal corrosion experiments were conducted in 316 stainless steel autoclaves at GE Global Research Center (Schenectady, NY) for five weeks. The specimens were hung up on an insulation coated 304 stainless steel wire. Three LWR coolant environments were simulated: pressurized water reactor (PWR), boiling water reactor (BWR) -normal water chemistry (NWC), and BWR-hydrogen water chemistry (HWC) conditions. The details of the coolant condition are summarized in Table 2. The PWR and BWR-HWC conditions were pressurized water environments at $\sim 300^{\circ} \mathrm{C}$ with hydrogen gas injections, which results in low Redox potential i.e. reducing activity environment. The BWR-NWC condition was similar condition to the BWR-HWC except for the presence of oxygen instead of hydrogen, which was high Redox potential i.e. oxidizing activity environment. The water chemistries were controlled by injection of appropriate mixtures of argon, oxygen, and hydrogen. The water flow rate during the tests was $200 \mathrm{ml} / \mathrm{min}$. One specimen of each type of the joint in each water chemistry condition was tested. The specimen of the SiC nanopowder sintered joint for the PWR condition was absent. The samples were extracted from the autoclaves after two weeks have passed to check presence or absence of complete dissolution or failure of the bonding layers, and then tested again in the newly built water flow. Details of the experimental were reported elsewhere [20]. Additives used in the coolant of commercial LWRs such as noble metals [21], which can affect the corrosion behavior, were absent in water of the autoclave. 
Table 2 Summary of environments of autoclave corrosion tests.

\begin{tabular}{ccccc}
\hline $\begin{array}{c}\text { Autoclave } \\
\text { Environment }\end{array}$ & Chemistry & $\begin{array}{c}\text { Temperature } \\
{\left[{ }^{\circ} \mathrm{C}\right]}\end{array}$ & $\mathrm{pH}$ & $\begin{array}{c}\text { Pressure } \\
{[\mathrm{MPa}]}\end{array}$ \\
\hline PWR & $3.57 \mathrm{ppm} \mathrm{H}_{2}$ & 330 & 7.2 & 15 \\
BWR-HWC & $0.3 \mathrm{ppm} \mathrm{H}_{2}$ & 290 & 5.6 & 7 \\
BWR-NWC & $1.0 \mathrm{ppm} \mathrm{O}_{2}$ & 290 & 5.6 & 7 \\
\hline
\end{tabular}

The recession rate of the SiC substrate was calculated from weight loss of the rectangular specimens, ignoring the bonding layer, because volume of the bonding layer within the corrosion specimen was less than $1.5 \%$. The relative recession of the bonding layer comparing with the substrate was usually evaluated by cross sectional analysis using a KEYENCE VHX-1000 optical microscope and a Hitachi 4800S or Versa 3D DualBeam scanning electron microscope (SEM). The recession of the specific specimen was evaluated using 3D imaging of the optical microscope because of the difficulty of the cross sectional specimen preparation. Elemental analysis was conducted using Energy-dispersive X-ray spectroscopy (EDS) using an AMETEK EDAX detector on the Hitachi 4800S. Electron Backscatter Diffraction Analysis (EBSD) was also conducted using an Oxford instruments an Oxford Instruments Nordlys detector on the Vresa SEM.

\section{Results and discussion}

\subsection{Corrosion behavior of SiC joints}

Appearances of the joint specimens following corrosion tests for five weeks are shown in Fig. 2. Most of the SiC joints withstood the corrosion tests except for the Ti diffusion joint tested in the BWR-NWC environment. The changes in the specimen thickness of the CVD SiC substrate and the bonding layers are summarized in Table 3. The recession of the CVD SiC was less than $1 \mu \mathrm{m} /$ week, which is consistent with previous work on the autoclave corrosion tests utilizing same grade of the material and water chemistries [18]. Since there was almost no recession of the CVD SiC substrate for this short term immersion tests, the observed relative recession of the bonding layer compared with the substrate is nearly equal to the recession of the bonding layer itself. An example of the appearance of the recession of the joint layer in the cross sectional observation is shown in Fig. 3. As shown in Table 3, the Mo diffusion bond exhibited significant recessions in all the water chemistries. There was no relative recession of the Ti diffusion 
bonding layer compared with the SiC substrate under the PWR and BWR-HWC. However, the joint layer failed during two to five weeks under the BWR-NWC test. There was also no relative recession of the bonding layer of Ti-Si-C reaction sintered joint compared with the SiC substrate under the PWR and BWR-HWC. On the other hand, gain of the joint thickness of the reaction sintered bond was confirmed by three dimensional optical microscope imaging as shown in Fig. 4. The SiC nanopowder sintered joint was the only joint which exhibited very limited recession of the bonding layer under both BWR-HWC and -NWC environments, though the recession was clearly observed under BWR-NWC using SEM shown later.

\begin{tabular}{|c|c|c|c|c|}
\hline \multirow{2}{*}{$\begin{array}{c}\text { Joint } \\
\text { Materials }\end{array}$} & \multicolumn{4}{|c|}{ Autoclave environment } \\
\cline { 2 - 5 } $\begin{array}{c}\text { Mo diffusion } \\
\text { bond }\end{array}$ & As-received & PWR & BWR-HWC & BWR-NWC \\
\hline $\begin{array}{c}\text { Ti diffusion } \\
\text { bond }\end{array}$ & 0 & 0 & 0 & \\
\hline $\begin{array}{c}\text { Ti-Si-C } \\
\text { reaction } \\
\text { sintered joint }\end{array}$ & 0 & 0 & & \\
\hline $\begin{array}{c}\text { LPS SiC joint } \\
\text { Lene joint failed. }\end{array}$ & & & \\
\hline
\end{tabular}

Fig. 2 Optical micrographs of SiC joint following corrosion tests for five weeks. The specimen dimensions are shown in Fig. 1.

Table 3 Changes in thickness of CVD SiC substrates and bonding layers after autoclave corrosion tests for five weeks. Unit for numbers is $\mu \mathrm{m}$. Values for joint materials indicate relative values compared with $\mathrm{SiC}$ substrate. Negative values indicate thickness loss.

\begin{tabular}{llll}
\hline Material & PWR & $\begin{array}{l}\text { BWR- } \\
\text { HWC }\end{array}$ & $\begin{array}{l}\text { BWR- } \\
\text { NWC }\end{array}$ \\
\hline SiC substrate & -0.20 & -0.05 & -0.25 \\
Mo diffusion bond & -110 & -95 & -235 \\
Ti diffusion bond & 0 & 0 & $>-750$ \\
Ti-Si-C reaction sintered joint & 0 & 0 & +35 \\
SiC nanopowder sintered joint & No data & 0 & -5 \\
\hline
\end{tabular}




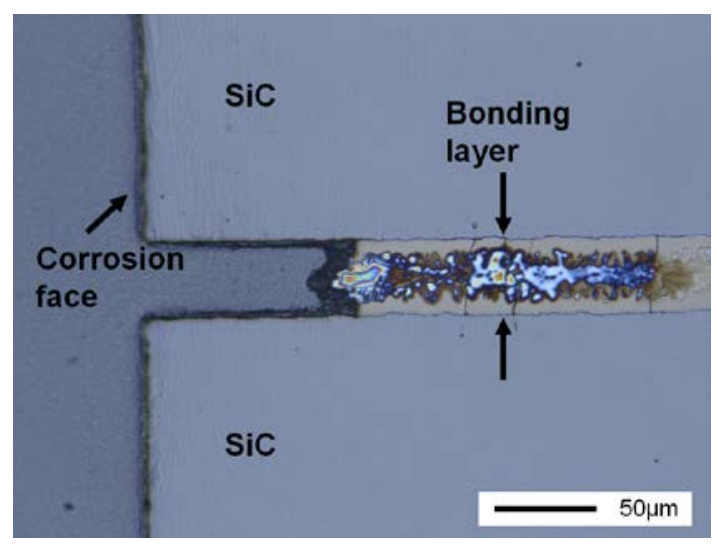

Fig. 3 Cross sectional optical micrograph of Mo foil bond after autoclave test with BWR-HWC for five weeks.

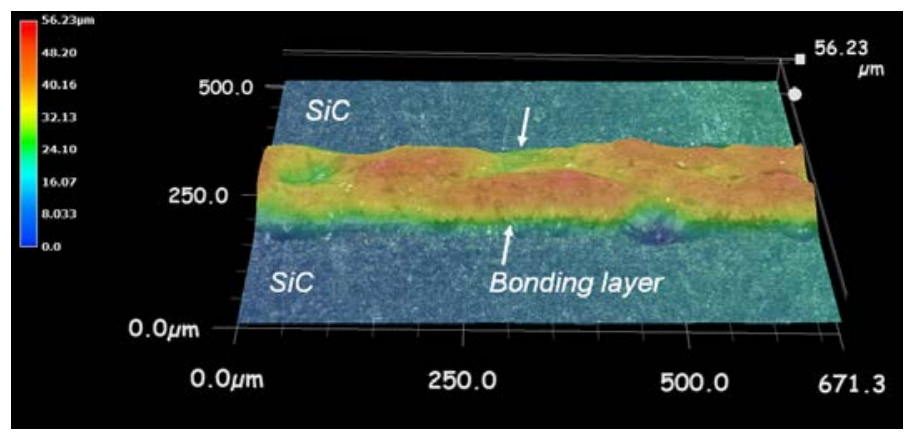

Fig. 4 Three dimensional optical micrograph of Ti-Si-C reaction sintered joint after BWR-NWC corrosion test for five weeks.

\subsection{Microstructural investigations of corroded joint}

(1) Mo diffusion bond

The phases in the Mo diffusion bond has been identified in previous study using X-ray diffraction [22]: a layer of ternary phase $\left(\mathrm{Mo}_{<5} \mathrm{Si}_{3} \mathrm{C}_{<1}\right)$ adjacent to the $\mathrm{SiC}$ interface and a middle layer of molybdenum carbide $\left(\mathrm{Mo}_{2} \mathrm{C}\right)$ as shown in Fig. 5. The thickness of the bonding layer was $\sim 30 \mu \mathrm{m}$. Pre-existing defects in the bonding layer were cracks propagating nearly vertical to the joint interface, which was likely caused by differential coefficients of thermal expansions between SiC substrate and the joint phases. Although the molybdenum carbide exhibited slightly smaller recession than the ternary phase, the recessions of the both joint phases were significant under the three water chemistries as shown in Table 3. 
The hydrothermal corrosion of the molybdenum ternary phase and carbide has not been reported in the literature. This study focused on discussion on possible methods to improve the poor performance of the Mo joint under the corrosion environments rather than the corrosion kinetics. The phases formed during diffusion of Si and C into Mo are (1) $\mathrm{Mo}_{5} \mathrm{Si}_{3}$ and $\mathrm{Mo}_{2} \mathrm{C}$ at $1200-1400^{\circ} \mathrm{C}$, (2) $\mathrm{Mo}_{<5} \mathrm{Si}_{3} \mathrm{C}_{<1}$ and $\mathrm{Mo}_{2} \mathrm{C}$ at $1400-1600^{\circ} \mathrm{C}$, and (3) $\mathrm{Mo}_{<5} \mathrm{Si}_{3} \mathrm{C}_{<1}$ and $\mathrm{MoC}$ at $1700^{\circ} \mathrm{C}$, depending on the thermodynamic stability of the phases [23]. It appears that the bonding layers consists of at least one of $\mathrm{Mo}_{<5} \mathrm{Si}_{3} \mathrm{C}_{<1}$ or $\mathrm{Mo}_{2} \mathrm{C}$ phases which was not corrosion resistant, thus conventional diffusion bonding with Mo interlayer is not promising for the LWR end-plug application without an environmental barrier coating. One possible way to improve the environmental resistance of the bulk Mo based material is by elemental doping [24]. However, at this time the processing of the elemental doping for the Mo joint layer has not been established.

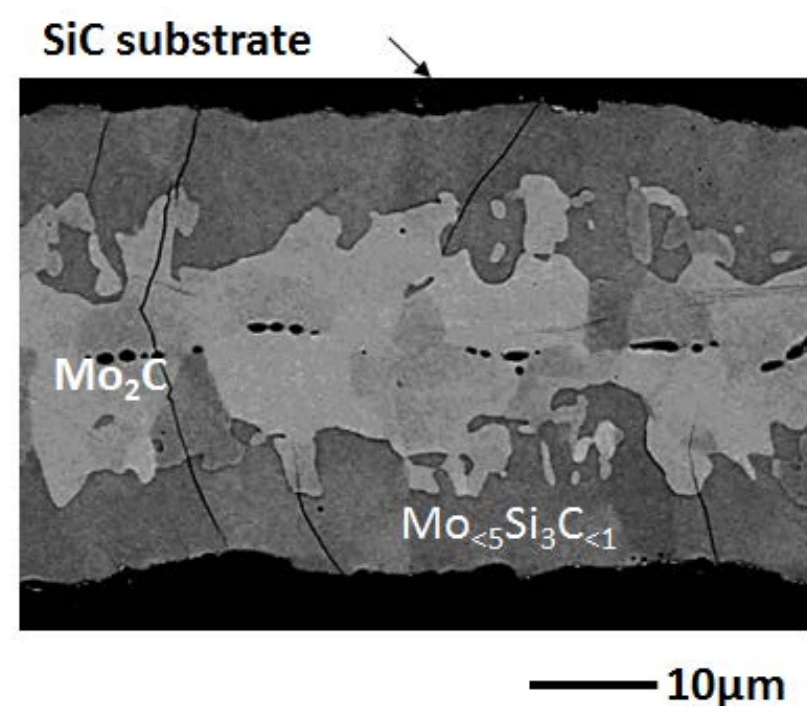

Fig. 5 Backscatter electron image of Mo diffusion bond.

\section{(2) Ti diffusion bond}

The bonding layer of the Ti diffusion bond was evaluated using EBSD analysis as shown in Fig. 6. The phase map revealed that the joint phase is a sole $\mathrm{Ti}_{3} \mathrm{SiC}_{2}$ phase. The joint thickness was $\sim 30 \mu \mathrm{m}$. The crystal orientation map shows there is no strong grain texture in both the $\mathrm{SiC}$ substrate and the $\mathrm{Ti}_{3} \mathrm{SiC}_{2}$ phase. The grain size of the $\mathrm{Ti}_{3} \mathrm{SiC}_{2}$ was more than a few microns in most cases. Note that low density cracks were observed in the bonding layer before the corrosion tests. Considering the stoichiometry, 
silicon was produced during reaction between $\mathrm{SiC}$ and $\mathrm{Ti}$ to form $\mathrm{Ti}_{3} \mathrm{SiC}_{2}$. The silicon may react to $\mathrm{Ti}$ to form finely dispersed $\mathrm{TiSi}_{2}$ or evaporated during the joining [25].

(a)

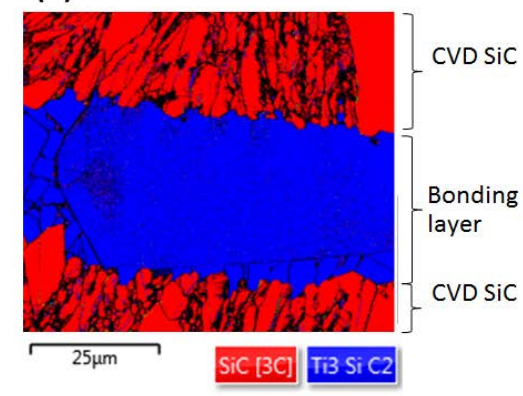

(b)

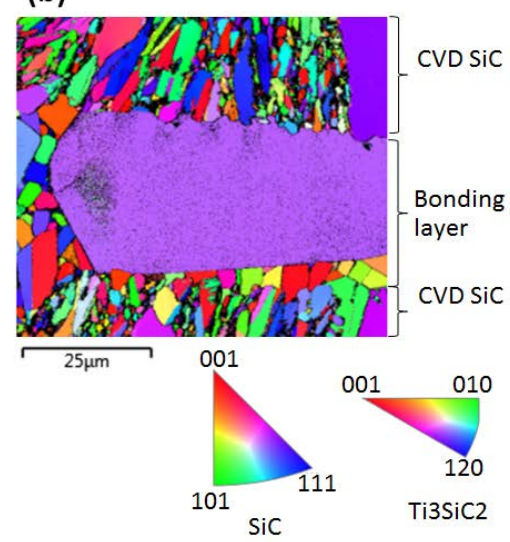

Fig. 6 Microstructures of Ti diffusion bond obtained by EBSD analysis: (a) phase map and (b) surface normal-projected inverse pole figure orientation map.

Cross sectional microstructural characterization was conducted for the joints tested under the PWR and BWR-HWC conditions. No difference of the recession between the $\mathrm{Ti}_{3} \mathrm{SiC}_{2}$ phase and $\mathrm{SiC}$ substrate was observed in SEM as shown in Fig. 7. The chemical composition of the corroded bonding layers was investigated by SEM-EDS. The EDS spectra shown in Fig. 8 were collected by area analysis. Very similar results were obtained from the joints tested in PWR and BWR-HWC; oxidation of the bonding layer was detected at the very surface of the corrosion face, however relatively limited amount of oxygen was confirmed in the area $\sim 10 \mu \mathrm{m}$ away from the corrosion face. The limited recession and oxidation of the Ti diffusion bond indicate that this joint is promising under those two hydrogen injected water chemistries without irradiation. Note that the joint failed apart during testing with BWR-NWC, so the Ti diffusion bond was obviously not stable under the oxidizing activity environment. 
(a) PWR

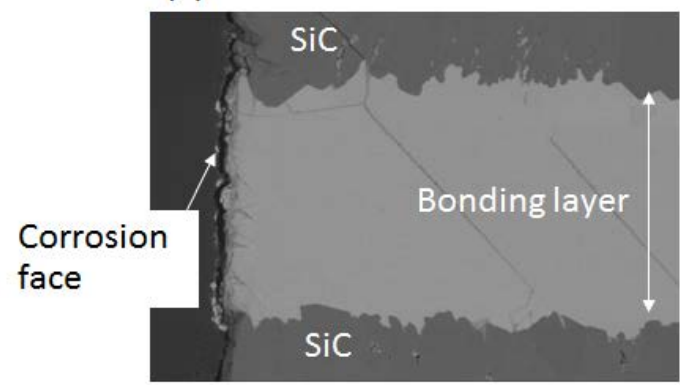

(b) BWR-HWC

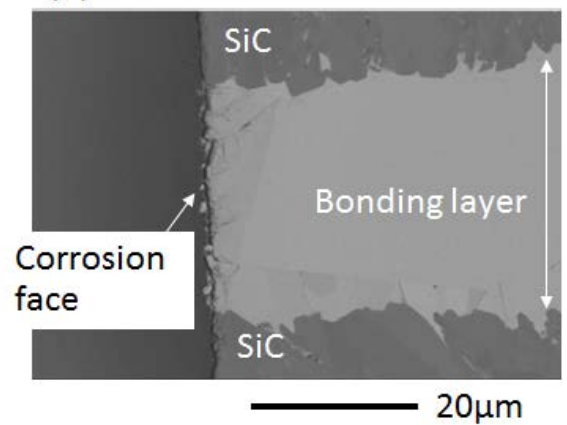

Fig. 7 Cross sectional backscatter images of Ti foil diffusion bond after autoclave immersion: (a) PWR and (b) BWR-HWC conditions.

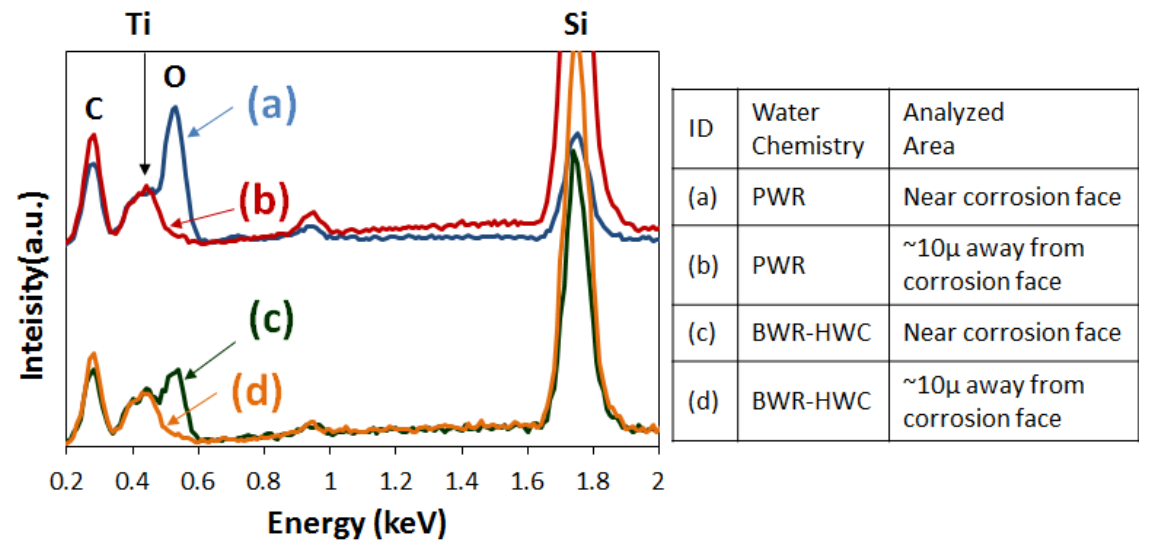

Fig. 8 EDS spectra collected from cross sectional prepared bonding layer of Ti diffusion bond after autoclave corrosion tests. The water chemistry and the analyzed area are shown in the table.

Zhang et al. investigated hydrothermal oxidation of the bulk $\mathrm{Ti}_{3} \mathrm{SiC}_{2}$ up to $100 \mathrm{~h}$ using an autoclave at 500,600 , and $700^{\circ} \mathrm{C}$ under a hydrostatic pressure of $35 \mathrm{MPa}$ [26]. The proposed hydrothermal oxidation reaction below $550^{\circ} \mathrm{C}$ was as follows.

$\mathrm{Ti}_{3} \mathrm{SiC}_{2}+9 \mathrm{H}_{2} \mathrm{O}=3 \mathrm{TiO}_{2}+\mathrm{SiO}_{2}+1 / 2 \mathrm{CO}_{2}+3 / 2 \mathrm{CH}_{4}+6 \mathrm{H}_{2}$

During this reaction, the formed $\mathrm{SiO}_{2}$ dissolved in the water. They found the oxide $\left(\mathrm{TiO}_{2}\right)$ layer on the corrosion surface after the corrosion tests, which is consistent with the detection of oxide only near the surface of the Ti diffusion bond under the PWR and BWR-HWC. On the other hand, they did not report a catastrophic oxidation or severe damage of $\mathrm{Ti}_{3} \mathrm{SiC}_{2}$, which is inconsistent with the failure of the $\mathrm{Ti}$ 
diffusion bond under BWR-NWC. Based on the significant effects of water chemistry on the corrosion behavior of the Ti diffusion bond in this study, the water chemistry in Zhang's study is expected to be a reducing activity environment, though there was no information of the oxygen concentration provided in that paper. One way to modify the corrosion resistance of $\mathrm{Ti}_{3} \mathrm{SiC}_{2}$ may be elemental doping. Although the doing method has not been applied to the joint yet, the improved corrosion resistance by doping of $\mathrm{Al}$ was demonstrated using an autoclave tests at $500-700^{\circ} \mathrm{C}[27]$.

(3) Ti-Si-C reaction sintered bond

The EBSD analysis identified the phases in the Ti-Si-C reaction sintered joint without the corrosion test (Fig. 9). The phase map shows that the dominant joint phases were $\mathrm{Ti}_{3} \mathrm{SiC}_{2}$ and $\mathrm{SiC}$ (mainly $6 \mathrm{H}$ or $4 \mathrm{H}$ hexagonal structure) and the minor phase was $\mathrm{TiC}$. Presence of the both $\mathrm{Ti}_{3} \mathrm{SiC}_{2}$ and $\mathrm{SiC}$ were also reported in the other Ti-Si-C reaction sintered joints [8]. The volume fractions of the phases were roughly $\mathrm{Ti}_{3} \mathrm{SiC}_{2}: \mathrm{SiC}: \mathrm{TiC}=4: 4: 2$. No strong texture of the grains was observed in the crystal orientation map. The joint thickness was typically $\sim 150 \mu \mathrm{m}$. Grain sizes were a few microns for $\mathrm{Ti}_{3} \mathrm{SiC}_{2}$ and $\mathrm{TiC}$ and $\sim 15 \mu \mathrm{m}$ for $6 \mathrm{H}$ and $4 \mathrm{H}$ SiC. Pre-existing defects were cracks propagating vertical to the joint interface.

(a)

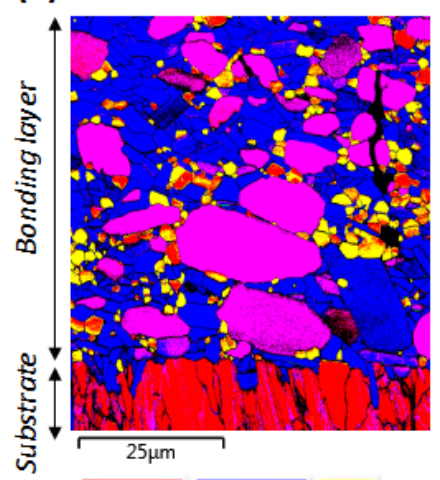

(b)
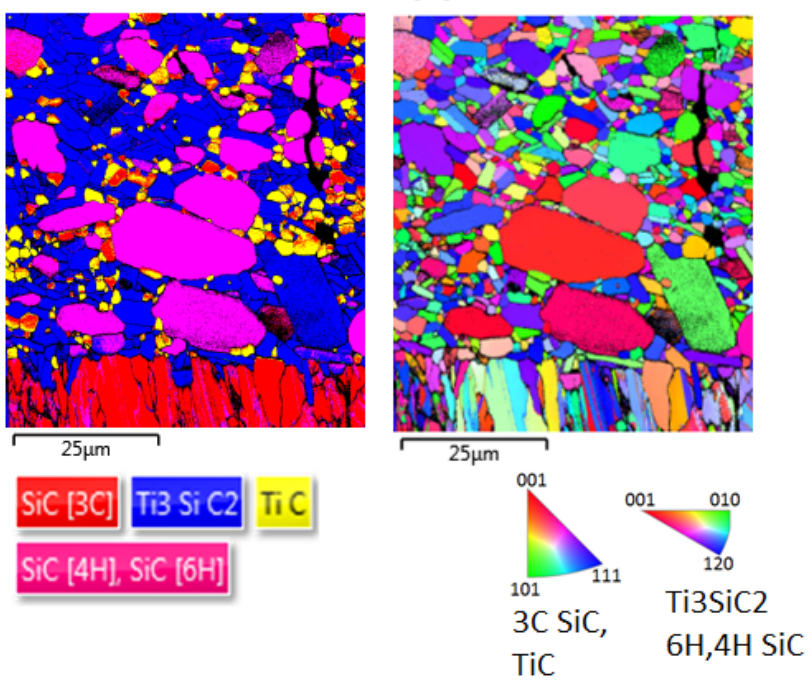

Fig. 9 Microstructure of Ti-Si-C reaction sintered joint obtained by EBSD: (a) phase map and (b) surface normal-projected inverse pole figure orientation map. 
Cross sections of the bonding layers were observed following the autoclave tests. No obvious recession of the bonding layer was observed after the PWR and BWR-HWC tests (Fig. 10), which is reasonable based on the corrosion resistant Ti diffusion bond containing $\mathrm{Ti}_{3} \mathrm{SiC}_{2}$ under those conditions. The EDS elemental maps in Fig. 10 show the limited and uniform presence of oxygen in the $\mathrm{Ti}_{3} \mathrm{SiC}_{2}$ and $\mathrm{TiC}$ phases. Oxygen can be dissolved in Ti during the fabrication at relatively low temperatures $\left(<1000^{\circ} \mathrm{C}\right)$ [28]. Following the PWR and BWR-HWC corrosion tests, local oxidations inside the bonding layer, 50 $\mu \mathrm{m}$ away from the corrosion face, were detected (Fig. 10). Although the effect of the local oxidation on the joint functionalities such as strength and gas leak-tightness are unknown from this study, the $\mathrm{Ti}_{3} \mathrm{SiC}_{2} / \mathrm{SiC}$ bonding layer appeared to be corrosion resistant under the PWR and BWR-HWC reducing activity environments based on the recession rate. In case of the oxidizing activity BWR-NWC environment, the bonding layer was failed during cutting specimens with a diamond saw for preparation of the polished cross section. This result indicates the bonding layer was highly damaged under the BWR-NWC. The failure location was the joint/substrate interface as shown in Fig. 10, which indicates that the hydrothermal oxidation weakened bonding at the interface. The EDS mapping revealed that the bonding layer, especially for the $\mathrm{Ti}_{3} \mathrm{SiC}_{2}$ phase (plus $\mathrm{TiC}$ phase), was highly oxidized. 


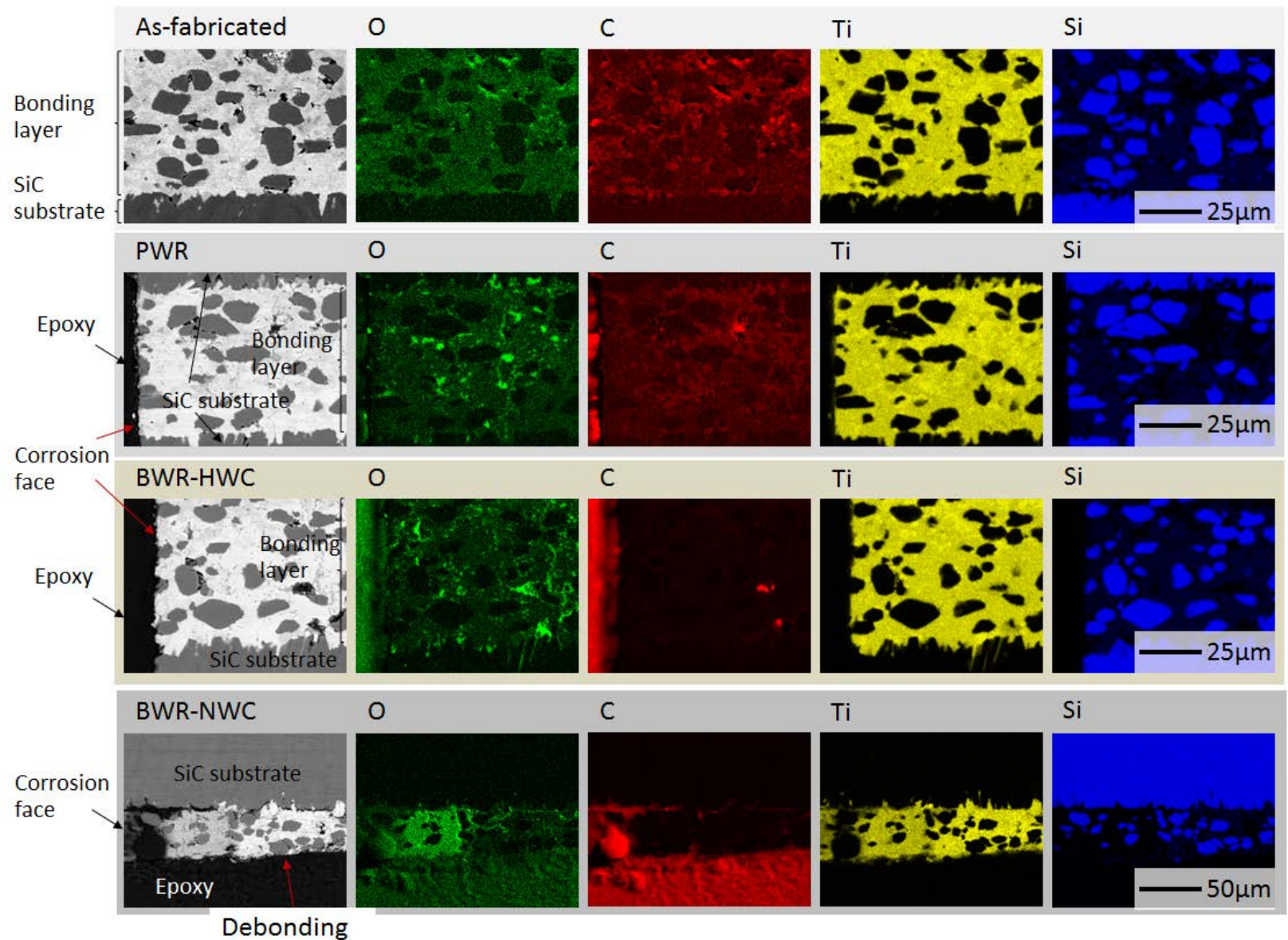

Fig. 10 Backscatter electron micrographs and EDS elemental maps of Ti-Si-C reaction sintered joints in as fabricated condition and after corrosion tests under PWR, BWR-HWC, and BWR-NWC.

Although both Ti-Si-C reaction sintered joint and $\mathrm{Ti}$ diffusion bond contained $\mathrm{Ti}_{3} \mathrm{SiC}_{2}$ phase as a dominant joint phase, a different corrosion behavior was observed. Under the reducing activity environments, the oxidation was found only at the corrosion face for the Ti diffusion bond, but found inside the bonding layer for the reaction sintered joint. Under the oxidizing activity environment, the diffusion bond failed, but the reaction sintered joint withstood the corrosion test. Considering the microstructural difference between the two joints, possible causes of the difference are (1) grain boundary diffusion of oxygen, and (2) effects of the secondary phases on the oxidation. However, the detailed mechanism of the oxidation is still not clear at this moment. One conclusion is that the material microstructures strongly affected the hydrothermal corrosion behavior of the $\mathrm{Ti}_{3} \mathrm{SiC}_{2}$ based bonding layer. 
(4) SiC nanopowder sintered joint

The SiC nanopowder sintered joint was the only joint, which exhibited limited recession of the bonding layer under both the reducing and oxidizing activity environments among the joints investigated, as shown in Table 3 and Fig. 11. The backscattered electron images shows that the bonding layer consisted of SiC grains (gray contrast) with the sizes of $0.5-1 \mu \mathrm{m}$ and oxide phases (white contrast) attributed to the sintering additives. The oxide phases were finely dispersed rather than forming a network. The joint thickness was $\sim 100 \mu \mathrm{m}$. Cross-sectional observation of the corrosion face showed no obvious recession of the bonding layer relative to the $\mathrm{SiC}$ substrate and $\sim 5 \mu \mathrm{m}$ relative thickness loss of the joint layer after the test with BWR-HWC and BWR-NWC, respectively. Under the BWR-HWC, there was no detectable microstructural change in the SEM micrograph. On the other hand, the oxide phases and the grain boundaries were preferentially attacked near the corrosion surface in the BWR-NWC condition (Fig. 11 (d)). The EDS elemental mapping (Fig. 12) revealed that the oxide phases consisted of aluminum, yttrium, and zirconium in as-fabricated condition. The detection of the substantial amount of zirconium in the oxide phases was unexpected since the sintering additives used were only alumina and yttria. The zirconium contamination likely came from the media of the ball milling during the processing. The rough estimation of the oxide content in the bonding layer based on the EDS analysis was

Al:Y:Zr:O=1.7:2:5.1:1(wt.\%). After the corrosion tests with the BWR-HWC and -NWC, aluminum was almost entirely depleted from the oxide phases near the corrosion faces. In contrast, yttrium, oxygen, and zirconium still remained in the oxide phases.

Based on the Al depletions under the BWR-HWC and -NWC and grain boundaries preferentially attached under the BWR-HWC, a key to control the corrosion resistance of the SiC nanopowder sintered joint is the optimization of the oxide phases. The oxide phases in this type of SiC ceramics usually exist not only at the grain pockets but also between the grain boundaries as a thin film with a nanometer thickness [29]. Kim et al reported the superior hydrothermal corrosion resistance of the high-purity CVD SiC compared to a solid-state sintered SiC with additives of boron and carbon as sintering additives [30]. This work also suggests the importance of controlling secondary phases to optimize the corrosion resistance. An idea to improve the corrosion resistance is the reduction of the oxide phases. Sintering $\mathrm{SiC}$ nano-powder required much smaller amount of alumina-yttria sintering additives than sintering micron sized SiC powder [15]. The minimum amount of the additives reported for alumina-yttria system was $\sim 5$ wt.\% [31, 32]. Another way to control the oxide phases is fabrication with different additive system. Noviyanto et al. investigated various systems of the sintering additives for SiC [32]. It was concluded that $\mathrm{Al}_{2} \mathrm{O}_{3}, \mathrm{MgO}, \mathrm{Y}_{2} \mathrm{O}_{3}$ and their mixed systems were found to be the effective sintering additives. Terrani et al. pursed new additives systems for SiC nanopowder sintering and demonstrated better hydrothermal 
oxidation resistance of bulk sintered $\mathrm{SiC}$ with yttria-zirconia(-limited amount of alumina) with respect to the SiC with conventional alumina-yttria system [33]. This modification of the sintering additives is applicable to the joining process.
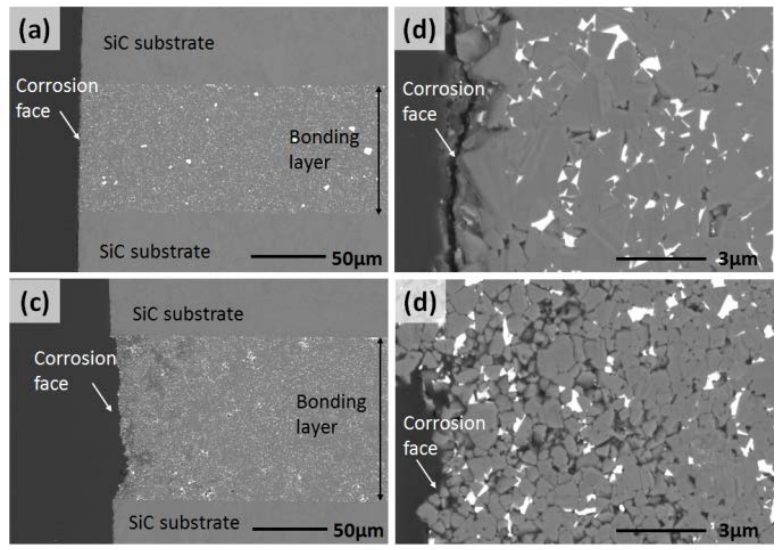

Fig. 11 Backscattered electron images of cross-section SiC nanopowder sintered joint after autoclave corrosion tests for five weeks: (a, b) BWR-HWC condition, (c, d) BWR-NWC condition. 


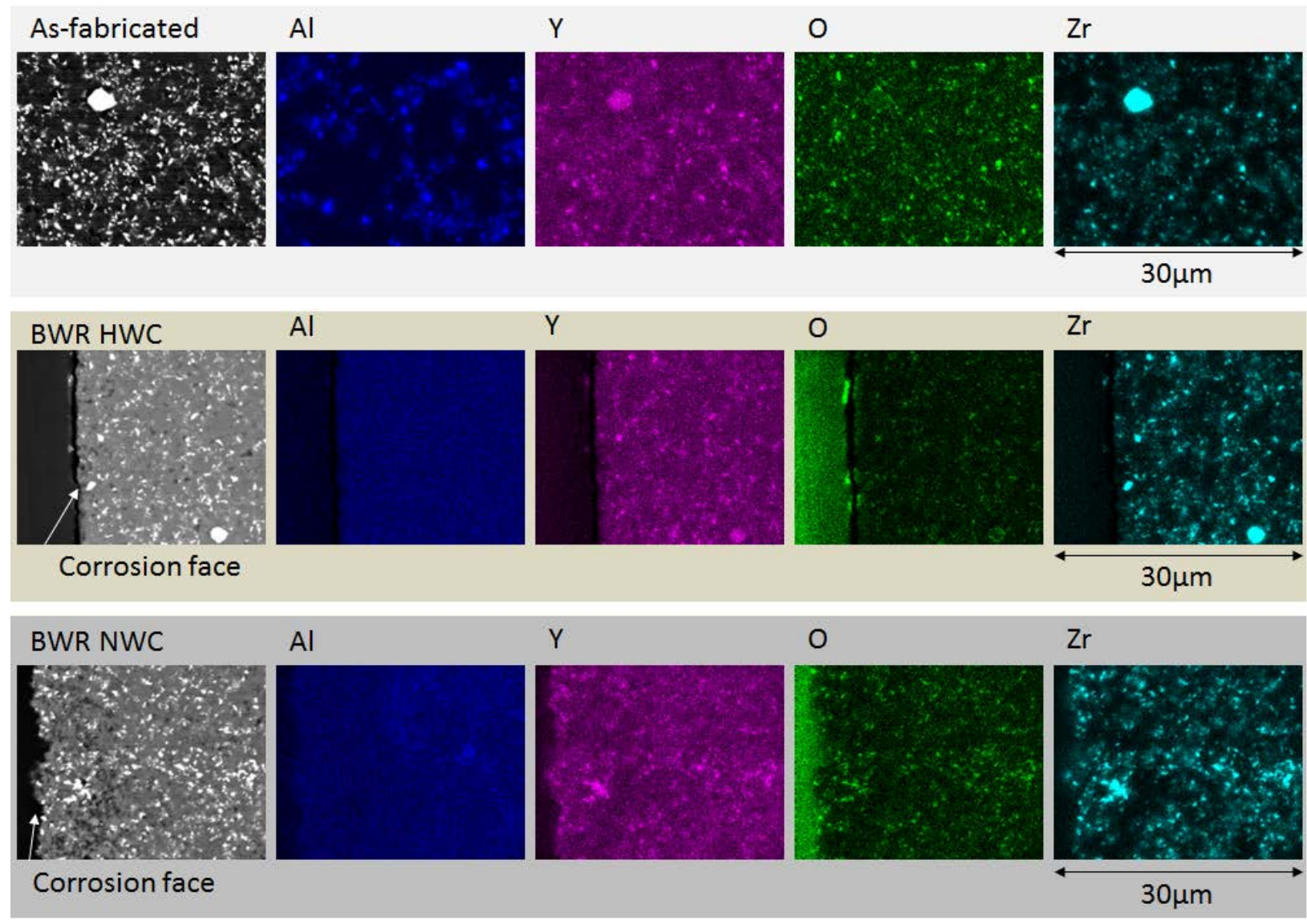

Fig. 12 Backscatter electron images and EDS elemental maps of as-fabricated and autoclave tested bonding layers of $\mathrm{SiC}$ nanopowder sintered joint.

\section{Future direction}

This paper studies hydrothermal corrosion behavior of the SiC joints under the simulated LWR coolant environments using the autoclave. Since neutron irradiation was absent in this test, the effects of radiolysis of light water and effects of irradiation-induced property changes of material on the corrosion were not studied. An in-pile corrosion experiment of SiC conducted by Carpenter [34] indicated that radiolysis and/or irradiation induced defects significantly affects the corrosion behavior of SiC tubes, depending on the material quality. Recent autoclave hydrothermal oxidation experiment using ion irradiated SiC indicates that irradiation-induced defect significantly affects the corrosion of SiC [35]. This radiation assisted corrosion can also occur in the phases of the bonding layers. Therefore, understanding the effects of irradiation under LWR condition on the SiC joints and evaluation of in-pile corrosion resistance of the $\mathrm{SiC}$ joints would be important next steps for the development of the SiC joining technology for the accident tolerant LWR cladding. 


\section{Conclusion}

Hydrothermal corrosion behavior of SiC joints was investigated under PWR, BWR-HWC, and BWRHWC without irradiation for five weeks. The findings are as follows.

(1) The CVD SiC substrate exhibited limited recession rate under the simulated LWR coolant environments.

(2) Both $\mathrm{Mo}_{<5} \mathrm{Si}_{3} \mathrm{C}_{<1}$ and $\mathrm{Mo}_{2} \mathrm{C}$ phases in the Mo diffusion bond showed significant recession in all three water chemistries. Based on the possible phases formed under Mo-SiC solid state diffusion, it was concluded that conventional Mo diffusion bonding does not provide corrosion resistant joint under the LWR coolant environments.

(3) The bonding layer of Ti diffusion bond with the single bonding phase of $\mathrm{Ti}_{3} \mathrm{SiC}_{2}$ showed the recession rate comparable to the CVD SiC substrate under the reducing activity environments (PWR and BWR-HWC). In addition, oxidation of the bonding layer was observed only near the corrosion face. On the other hand, the joint failed during the corrosion test under the oxidizing activity (BWR-NWC).

(4) The Ti-Si-C reaction sintering provided the bonding layer consisting of dominant phases of $\mathrm{Ti}_{3} \mathrm{SiC}_{2}$ and $\mathrm{SiC}$ and minor phase of $\mathrm{TiC}$. The recession of the bonding layer was limited under the reducing activities, but local oxidation was observed away from the corrosion face. The joint was highly oxidized under the oxidizing activity. The differential corrosion behavior between the Ti diffusion and the reaction sintered bonds indicates that the microstructure of $\mathrm{Ti}_{3} \mathrm{SiC}_{2}$ such as presence of secondary phase and grain boundaries affects the hydrothermal oxidation.

(5) The SiC nanopowder sintering method formed the SiC based bonding layer with the Al-Y-Zr oxide phases. This joint was the only one showing limited recession under both the reducing and oxidizing activity environments in this study. Controlling the oxide phases and distribution is a key to improve the hydrothermal oxidation resistance.

\section{Acknowledgements}

This work was sponsored by the U.S. Department of Energy, Office of Nuclear Energy, for the Fuel Cycle Research \& Development program under contact DE-AC05-00OR22725 with Oak Ridge National Laboratories managed by UT-Battelle, LLC. 


\section{References}

[1] Y. Katoh, L.L. Snead, C.H. Henager, T. Nozawa, T. Hinoki, A. Iveković, S. Novak, S.G. de Vicente, Current status and recent research achievements in $\mathrm{SiC} / \mathrm{SiC}$ composites, Journal of Nuclear Materials 455(1) (2014) 387-397.

[2] S.J. Zinkle, K.A. Terrani, J.C. Gehin, L.J. Ott, L.L. Snead, Accident tolerant fuels for LWRs: A perspective, Journal of Nuclear Materials 448(1) (2014) 374-379.

[3] J.D. Stempien, D.M. Carpenter, G. Kohse, M.S. Kazimi, Characteristics of composite silicon carbide fuel cladding after irradiation under simulated PWR conditions, Nuclear Technology 183(1) (2013) 1329.

[4] Y. Katoh, L.L. Snead, T. Cheng, C. Shih, W.D. Lewis, T. Koyanagi, T. Hinoki, C.H. Henager, M. Ferraris, Radiation-tolerant joining technologies for silicon carbide ceramics and composites, Journal of Nuclear Materials 448(1) (2014) 497-511.

[5] B. Cockeram, The diffusion bonding of silicon carbide and boron carbide using refractory metals, Bettis Atomic Power Lab., West Mifflin, PA (US), 1999.

[6] J. Sha, T. Nozawa, J. Park, Y. Katoh, A. Kohyama, Effect of heat treatment on the tensile strength and creep resistance of advanced SiC fibers, Journal of nuclear materials 329 (2004) 592-596.

[7] B. Cockeram, Flexural strength and shear strength of silicon carbide to silicon carbide joints fabricated by a molybdenum diffusion bonding technique, Journal of the American Ceramic Society 88(7) (2005) 1892-1899.

[8] C.H. Henager, R.J. Kurtz, Low-activation joining of SiC/SiC composites for fusion applications, Journal of Nuclear Materials 417(1) (2011) 375-378.

[9] C. Racault, F. Langlais, R. Naslain, Solid-state synthesis and characterization of the ternary phase Ti3SiC2, Journal of materials Science 29(13) (1994) 3384-3392.

[10] L.L. Zheng, L.C. Sun, M.S. Li, Y.C. Zhou, Improving the High-Temperature Oxidation Resistance of Ti3 (SiAl) C2 by Nb-Doping, Journal of the American Ceramic Society 94(10) (2011) 3579-3586.

[11] J. Lee, Y. Katoh, A. Kohyama, SiC and Si3N4 Ceramic Joining by Transient Eutectic Phase Process, 27th Annual Cocoa Beach Conference on Advanced Ceramics and Composites: B: Ceramic Engineering and Science Proceedings, Volume 24, Issue 4, Wiley Online Library, 2003, pp. 325-330.

[12] T. Hinoki, N. Eiza, S. Son, K. Shimoda, J. Lee, A. Kohyama, Development of joining and coating technique for $\mathrm{SiC}$ and $\mathrm{SiC} / \mathrm{SiC}$ Composites utilizing NITE processing, Mechanical Properties and Performance of Engineering Ceramics and Composites: Ceramic Engineering and Science Proceedings, Volume 26, Number 2 (2005) 399-405.

[13] W. Kingery, Densification during sintering in the presence of a liquid phase. I. Theory, Journal of Applied Physics 30(3) (1959) 301-306.

[14] K.A. Terrani, J. Kiggans, C.M. Silva, C. Shih, Y. Katoh, L.L. Snead, Progress on matrix SiC processing and properties for fully ceramic microencapsulated fuel form, Journal of Nuclear Materials 457 (2015) 9-17.

[15] K. Shimoda, N. Eiza, J.-S. Park, T. Hinoki, A. Kohyama, S. Kondo, High-temperature mechanical property improvements of SiC ceramics by NITE process, Materials transactions 47(4) (2006) 1204-1208.

[16] T. Koyanagi, S. Kondo, T. Hinoki, The influence of sintering additives on the irradiation resistance of NITE SiC, Journal of Nuclear Materials 417(1) (2011) 435-439.

[17] M. Ferraris, M. Salvo, V. Casalegno, S. Han, Y. Katoh, H. Jung, T. Hinoki, A. Kohyama, Joining of SiC-based materials for nuclear energy applications, Journal of Nuclear Materials 417(1) (2011) 379-382. [18] C.A. Lewinsohn, R.H. Jones, P. Colombo, B. Riccardi, Silicon carbide-based materials for joining silicon carbide composites for fusion energy applications, Journal of Nuclear Materials 307 (2002) 12321236.

[19] H. Khalifa, C. Deck, O. Gutierrez, G. Jacobsen, C. Back, Fabrication and characterization of joined silicon carbide cylindrical components for nuclear applications, Journal of Nuclear Materials 457 (2015) 227-240. 
[20] K.A. Terrani, Y. Yang, Y.-J. Kim, R. Rebak, H. Meyer, T.J. Gerczak, Hydrothermal corrosion of SiC in LWR coolant environments in the absence of irradiation, Journal of Nuclear Materials 465 (2015) 488498.

[21] Y.-J. Kim, L.W. Niedrach, M.E. Indig, P.L. Andresen, The application of noble metals in light-water reactors, JOM 44(4) (1992) 14-18.

[22] T. Koyanagi, J. Kiggans, C. Shih, Y. Katoh, PROCESSING AND CHARACTERIZATION OF DIFFUSION-BONDED SILICON CARBIDE JOINTS USING MOLYBDENUMAND TITANIUM INTERLAYERS, Ceramic Materials for Energy Applications IV: Ceramic Engineering and Science Proceedings, Volume 35 (7) (2015) 151.

[23] A. Martinelli, R. Drew, Microstructural development during diffusion bonding of $\alpha$-silicon carbide to molybdenum, Materials Science and Engineering: A 191(1) (1995) 239-247.

[24] M.K. Meyer, M. Akinc, Oxidation Behavior of Boron-Modified Mo5Si3 at $800^{\circ}-1300^{\circ}$ C, Journal of the American Ceramic Society 79(4) (1996) 938-944.

[25] B. Gottselig, E. Gyarmati, A. Naoumidis, H. Nickel, Joining of ceramics demonstrated by the example of SiC/Ti, Journal of the European Ceramic Society 6(3) (1990) 153-160.

[26] H. Zhang, V. Presser, C. Berthold, K.G. Nickel, X. Wang, C. Raisch, T. Chasse, L. He, Y. Zhou, Mechanisms and kinetics of the hydrothermal oxidation of bulk titanium silicon carbide, Journal of the American Ceramic Society 93(4) (2010) 1148-1155.

[27] H. Zhang, X. Wang, C. Berthold, K. Nickel, Y. Zhou, Effect of Al dopant on the hydrothermal oxidation behavior of Ti 3 SiC 2 powders, Journal of the European Ceramic Society 29(10) (2009) 20972103.

[28] P. Kofstad, P. Anderson, O. Krudtaa, Oxidation of titanium in the temperature range 800-1200 C, Journal of the Less Common Metals 3(2) (1961) 89-97.

[29] T. Koyanagi, S. Kondo, T. Hinoki, Microstructural analysis of secondary phases in silicon carbide fabricated with $\mathrm{SiC}$ nano-powder and sintering additives, Ceramic Engineering and Science Proceedings, American Ceramic Society, Inc., 735 Ceramic Place Westerville OH 43081 United States, 2011, pp. 5361.

[30] W.-J. Kim, H.S. Hwang, J.Y. Park, W.-S. Ryu, Corrosion behaviors of sintered and chemically vapor deposited silicon carbide ceramics in water at 360 C, Journal of materials science letters 22(8) (2003) 581-584.

[31] K.A. Terrani, J. Kiggans, Y. Katoh, K. Shimoda, F.C. Montgomery, B.L. Armstrong, C.M. Parish, T. Hinoki, J.D. Hunn, L.L. Snead, Fabrication and characterization of fully ceramic microencapsulated fuels, Journal of Nuclear Materials 426(1) (2012) 268-276.

[32] A. Noviyanto, D.-H. Yoon, Metal oxide additives for the sintering of silicon carbide: Reactivity and densification, Current Applied Physics 13(1) (2013) 287-292.

[33] K. Terrani, Y. Katoh, C.M. Parish, Y.-J. Kim, Fabrication and Hydrothermal Corrosion of NITE-SiC with Various Sintering Additives, 40th International Conference and Expo on Advanced Ceramics and Composites, The American Ceramics Society, Daytona Beach, Florida, USA, 2016.

[34] D.M. Carpenter, An assessment of silicon carbide as a cladding material for light water reactors, Massachusetts Institute of Technology, 2010.

[35] S. Kondo, M. Lee, T. Hinoki, Y. Hyodo, F. Kano, Effect of irradiation damage on hydrothermal corrosion of SiC, Journal of Nuclear Materials 464 (2015) 36-42. 
Irradiation resistance of silicon carbide joint at light water reactor relevant temperature

T. Koyanagi ${ }^{1}$, Y. Katoh ${ }^{1}$, J.O. Kiggans ${ }^{1}$, T. Hinoki ${ }^{2}$, H.E. Khalifa ${ }^{3}$, C.P. Deck ${ }^{3}$, C.A. Back $^{3}$

1 Oak Ridge National Laboratory, USA

2 Kyoto University, Japan

3 General Atomics, USA

\begin{abstract}
Monolithic silicon carbide (SiC) to SiC plate joints were fabricated and irradiated with neutrons at $\sim 300^{\circ} \mathrm{C}$ to 8.7 displacement per atom for SiC. The joining methods include solid state diffusion bonding utilizing titanium and molybdenum interlayers, SiC nanopowder sintering, reaction sintering with Ti-Si-C system, and hybrid processing of polymer pyrolysis and chemical vapor infiltration (CVI). All the irradiated joints exhibited apparent shear strength of more than $80 \mathrm{MPa}$ on average. Significant irradiation-induced cracking was found in the bonding layers of the Ti and Mo diffusion bonds and Ti-Si$\mathrm{C}$ reaction sintered bond. The SiC based bonding layers of the SiC nanopowder sintered joint and hybrid polymer pyrolysis and CVI joint showed stable microstructure following the irradiation.
\end{abstract}

\title{
1. Introduction
}

Silicon carbide (SiC) fiber reinforced SiC matrix composites have been widely studied for the development of an accident tolerant fuel cladding of light water reactors (LWRs) in recent years because of the superior oxidation and irradiation resistances, and the low neutron absorption cross section [1, 2]. Although SiC composites are very attractive, some technological hurdles such as fuel compatibility, hydrothermal corrosion, and manufacturability have been addressed [3]. Regarding implementation, a reliable joining technology is essential for the end-plug section of the clad. These joints are required to retain fission products inside the clad and withstand the reactor environments (irradiation and hydrothermal corrosion for the normal operation, and high temperature oxidation for the accident condition). This paper focuses on irradiation resistance of the candidate SiC joints. 
Katoh et al. has demonstrated irradiation tolerant joining technologies with neutron irradiations at 500 and $800^{\circ} \mathrm{C}$ [4]. The joining methods included titanium diffusion bonding, transient eutectic phase sintering, calcia-alumina glass ceramics joining, and Ti-Si-C based reaction sintering. Although all the joints did not show obvious strength degradation by the irradiations, irradiation-induced cracking was observed in the bonding layer of the non-SiC phases, which was likely caused by differential swelling between the bonding layers and $\mathrm{SiC}$ substrate. Since swelling of $\mathrm{SiC}$ shows negative temperature correlation [5], the issue of the differential swelling may be more critical at lower irradiation temperature. Therefore, irradiation resistance of the $\mathrm{SiC}$ joints at LWR coolant temperature $\left(\sim 300^{\circ} \mathrm{C}\right)$ is needed. In this study six types of plate to plate SiC joints were fabricated and irradiated. The radiation resistance of the joints was evaluated using a shear strength test and microstructural observations.

\section{Experimental details}

\subsection{Neutron irradiation and post-irradiation experiments}

Irradiation and post-irradiation testing methods of miniature SiC joint specimens were developed in our previous study [4]. This study utilized the very similar geometries of the specimens and irradiation vehicles used in that study. The neutron irradiation was conducted using the rabbit vehicles in the target irradiation facility of the High Flux Isotope Reactor at Oak Ridge National Laboratory. The specimens were irradiated at $270-310^{\circ} \mathrm{C}$ to 8.7 displacement per atom (dpa) for SiC $\left(1.0 \times 10^{25} \mathrm{n} / \mathrm{m}^{2}=1 \mathrm{dpa}\right.$ [E > $0.1 \mathrm{MeV}]$ is assumed.). The irradiation temperature was investigated by post-irradiation annealing of passive SiC temperature monitors using dilatometry [6]. The temperature monitors were irradiated in contact with the substrate of the joint specimens.

Shear strength of the joint test specimens was evaluated using hourglass-type specimens that had specifically been designed for the rabbit irradiation experiment [4]. The specimen geometries and appearance are shown in Fig. 1. The bonding layer located at the center of the specimen in 2.9-3.0 mm thickness direction. The neck diameter of the hourglass specimen was $4 \mathrm{~mm}$ for the SiC nanopowder sintered joints and $5 \mathrm{~mm}$ for the other joints. The deviation of the neck diameter was typically within 0.1 $\mathrm{mm}$ other than the hybrid polymer pyrolysis/CVI joint with the deviation of $0.2 \mathrm{~mm}$. The torsional test was conducted using TestResources 160GT-125Nm system with pairs of flexible couplers and sample grips (Fig. 2). The flexible coupling keeps the alignment during loading. Aluminum-alloy tabs were installed at the square grip sections to obtain uniform stress distributions there. The rotation speed was 0.15 degree/min. Nominal shear strength values $(\tau)$ in this work are given by following equation, 
$\tau=16 T / \pi d^{3}$

where $T$ is the applied torque and $d$ is the specimen diameter of the neck. The number of the torsion tests was 4-9 for the unirradiated specimens and three or four for the irradiated specimens. All the tests were conducted at a room temperature. The fracture appearance was visually observed or investigated using conventional optical microscope.
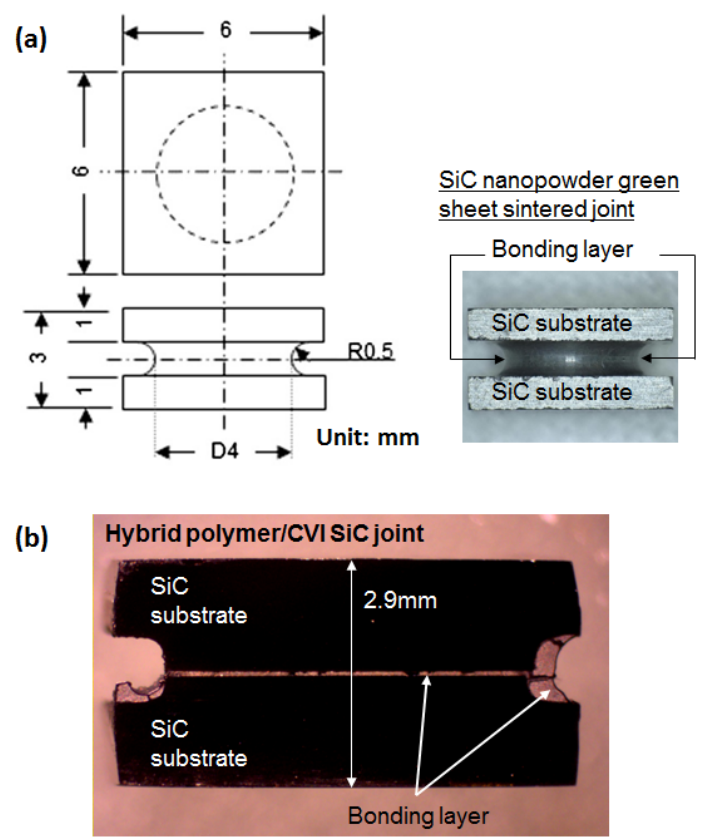

Fig. 1 Appearances of (a) unirradiated SiC nanopowder sintered joint formed with green sheet, and (b) unirradiated hybrid polymer pyrolysis/CVI SiC joint. 


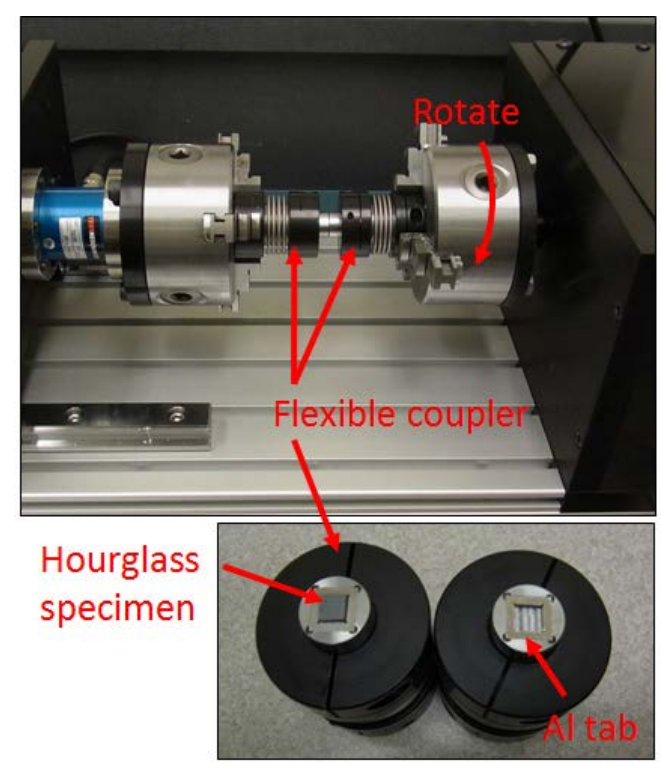

Fig. 2 Test apparatus of torsional shear test.

An examination of the cross sections of the unirradiated and irradiated joint specimens not subjected to do the torsional tests was conducted using scanning electron microscopes (SEM, field-emission (FE) gun type Hitachi 4800S and FE gun type FEI Versa 3D DualBeam SEM/focused ion beam). The specimens were cut using a diamond saw followed by mechanical polishing with diamond films and colloidal silica suspension. Elemental analysis was conducted using Energy-dispersive X-ray spectroscopy (EDS) using an AMETEK EDAX detector on the Hitachi 4800S SEM. Electron Backscatter Diffraction Analysis (EBSD) was conducted using an Oxford Instruments Nordlys detector on the FEI Versa SEM.

\subsection{Fabrication of SiC joints}

For the present irradiation experiment, SiC joints were prepared using diffusion bonding with the titanium and molybdenum foil inserts, SiC nanopowder sintering based joining using slurry and green tape, Ti-Si$\mathrm{C}$ based reaction sintering, and hybrid preceramic polymer/chemical vapor infiltration (CVI) joining, as summarized in Table 1. The substrates of all the joints were high-purity chemically vapor-deposited (CVD) SiC (Dow Chemical Co., Marlborough, Massachusetts). SiC bonded plate of all the joints other than hybrid polymer/CVI joint were fabricated followed by machining the miniature hourglass specimens. In case of the hybrid polymer/CVI joint, $\mathrm{SiC}$ substrates were machined into half pieces of the hourglass specimen, and then the joining was carried out between the halves. 
Table 1 Summary of SiC joining methods and the bonding phases.

\begin{tabular}{lll}
\hline Joining method & $\begin{array}{l}\text { Processing conditions } \\
\text { Temperature/Applied stress }\end{array}$ & Phases present in joint layer \\
\hline Ti foil diffusion & $1500^{\circ} \mathrm{C} / 17 \mathrm{MPa}$ & $\mathrm{Ti}_{3} \mathrm{SiC}_{2}, \mathrm{TiSi}_{2}$ \\
Mo foil diffusion & $1500^{\circ} \mathrm{C} / 20 \mathrm{MPa}$ & $\mathrm{Mo}_{4.8} \mathrm{Si}_{3} \mathrm{C}_{0.6}, \mathrm{Mo}_{2} \mathrm{C}$ \\
$\mathrm{SiC}$ nanopowder slurry sintering & $1850^{\circ} \mathrm{C} / 10 \mathrm{MPa}$ & $\mathrm{SiC}, \mathrm{Y}-\mathrm{Al}-\mathrm{Zr}$ oxides \\
SiC nanopowder green sheet sintering & $1850^{\circ} \mathrm{C} / 10 \mathrm{MPa}$ & $\mathrm{SiC}, \mathrm{Y}-\mathrm{Al}-\mathrm{Zr}$ oxides \\
Ti-Si-C based reaction sintering & Proprietary & $\mathrm{Ti}_{3} \mathrm{SiC}_{2}, \mathrm{SiC}$, minor $\mathrm{TiC}$ \\
Hybrid polymer pyrolysis/CVI & $\sim 1500^{\circ} \mathrm{C} /<1 \mathrm{MPa}$ & $\mathrm{SiC}$ \\
\hline
\end{tabular}

The interlayer of the Ti diffusion bond was a titanium foil (25 $\mu \mathrm{m}$ thick, 99.94\% pure, Alfa-Aesar, Ward Hill, MA). The joining of SiC/Ti foil/SiC sandwiches was accomplished by hot-pressing at $1500{ }^{\circ} \mathrm{C}$, for 1 $\mathrm{h}$, in vacuum, under a uniaxial pressure of $17 \mathrm{MPa}$. To reduce oxygen partial pressure in the furnace, titanium powder was used as the oxygen getter. A molybdenum foil ( $25 \mu \mathrm{m}$ thick, $99.95 \%$ pure, AlfaAesar, Ward Hill, MA) was used as an interlayer of the Mo diffusion bonding. The joining of SiC/Mo foil/SiC sandwiches was accomplished by hot-pressing at $1500^{\circ} \mathrm{C}$, for $1 \mathrm{~h}$, in flowing $\mathrm{Ar}-4 \% \mathrm{H}_{2}$ atmosphere, under a uniaxial pressure of $20 \mathrm{MPa}$. During the hot-pressing, the presence of both hydrogen and titanium powder facilitated effective oxygen gettering. Size of the SiC substrate was $21.0 \mathrm{~mm}(\mathrm{w}) \times$ $31.2 \mathrm{~mm}(\mathrm{l}) \times 6.2 \mathrm{~mm}(\mathrm{t})$ for both Ti and Mo diffusion bonds.

Two types of SiC nanopowder sintering based joint were prepared in this study: joining using mixed powder slurry and joining with a commercial green sheet. The green sheet consists of the feedstocks for SiC nanophase slurry plus organic binder to make the sheet enough strong and flexible to handle. The advantage to use the green sheet is an ease of control of the joint thickness. However, the substantial amount of organic additives in the sheet can affect quality of the final product. On the other hand, the slurry method does not require the organic additives so that high quality of the joint can be achieved. The drawback of the slurry method is the difficulty of the control of the joint thickness. To make the slurry, $\mathrm{SiC}$ nano-phase powder (average diameters $\sim 30 \mathrm{~nm}$, Nanomakers, France), and $\mathrm{Al}_{2} \mathrm{O}_{3}$ powder (average diameters $\sim 0.3 \mu \mathrm{m}$, Kojundo Chemical Lab. Co., Ltd., Japan), $\mathrm{Y}_{2} \mathrm{O}_{3}$ powder (average diameters $\sim 0.4 \mu \mathrm{m}$, Kojundo Chemical Lab. Co., Ltd., Japan) were dispersed in ethanol, and then mixed by milling with zirconia balls. The total amount of oxide additives was $6 \mathrm{wt} \%$ with weight ratio of $\mathrm{Al}_{2} \mathrm{O}_{3}: \mathrm{Y}_{2} \mathrm{O}_{3}=3: 2$. The slurry was sandwiched by CVD SiC plates, and then dried at $\sim 80^{\circ} \mathrm{C}$ prior to heating. After that, the joint was formed by hot-pressing at $1850^{\circ} \mathrm{C}$, for $1 \mathrm{~h}$, in an $\mathrm{Ar}$ atmosphere, under a pressure of $10 \mathrm{MPa}$. The 
feedstock of the green tape was same as that of the slurry sintered joint except for the additional use of organic binders. The green tape was provided by in Gunze ltd. in Japan. The joining of SiC/green tape/SiC sandwiches was accomplished by hot-pressing. The hot-pressing conditions were same as those for the SiC nanophase slurry sintered joint. The dimensions of the SiC substrate were $40 \mathrm{~mm}(\mathrm{w}) \times 40$ $\mathrm{mm}(\mathrm{l}) \times \sim 5 \mathrm{~mm}(\mathrm{t})$.

For Ti-Si-C reaction sintered joint, the joining agent material was purchased from Hyper-Therm High Temperature Composites, Inc. (currently Rolls-Royce High Temperature Composites, Inc., Huntington Beach, CA). The Ti-Si-C phase-based joints of CVD SiC were produced based on a pressure-less slurry process per the Hyper-Therm formula. Details of the raw materials and the process conditions are proprietary. The size of the bonding plate was same as those for the Ti and Mo diffusion bonds.

Bonding by hybrid preceramic polymer pyrolysis/CVI joining was formed by two-step processes. First, the half pieces of the hourglass specimens were joined using a SiC forming polymer with SiC whiskers. The polymer-driven bonding layer was typically porous. Next, the bonding layer was densified via CVI process. The maximum temperature and applied stress during the processing was $\sim 1500^{\circ} \mathrm{C}$ and $<1 \mathrm{MPa}$, respectively. The details of the processing method can be found elsewhere [7].

\section{Results and discussion}

\subsection{Effects of irradiation on strengths of SiC joints}

Results of the torsional shear tests are summarized in Fig. 3 and Table 2. The torsional shear test can provide true shear strength based on equation (1) if the following condition is satisfied: (1) shear failure of the specimen and (2) fracture initiated from the surface of the neck section. The fracture mode could be identified based on the fracture surface. However, clean shear failure did not occur for most types of the joint. In addition, the fracture initiation site could not be identified in this study since the multiple cracks were found after testing. Therefore, the obtained strength is an apparent shear strength, which is still useful to evaluate the irradiation effects on the joints. All types of joints except for the SiC nanopowder slurry sintered joint exhibited primary a shear strength of 90 to $150 \mathrm{MPa}$ in average. Relatively high average shear strengths of $320 \mathrm{MPa}$ were obtained from the SiC nanophase slurry sintered joints.

The typical fracture appearances of the unirradiated joints are shown in Fig. 4. All the SiC joints other than the SiC nanopowder sintered joint formed with green sheet and hybrid polymer pyrolysis/CVI joint showed the fracture surfaces of $\mathrm{SiC}$ substrate (Fig. 4(a)). The neck parts of those specimens were 
shattered into pieces during the test, which made identification of the fracture initiation site impossible. The hybrid polymer pyrolysis/CVI joint exhibited shear failure (Fig. 4(b)). The cracking is expected to initiate within the bonding plane or joint interface. The fracture appearance of the joints formed with SiC green sheet was the substrate failure (Fig. 4(b)) or failure partially at the boning plane (Fig. 4(c)). The torsional shear strength and the fracture appearance are expected to be affected by not only strength of bond at the joint interface but also strength of the bonding layer, internal residual stress, surface condition, and differential elastic modulus between bonding layer and SiC substrate.

Regarding the effect of the irradiation on the joint strength, the torsional tests revealed that the joint strength of Mo joints was likely degraded as shown in Fig.3. The large data scatter was observed for Ti diffusion bond and two types of the SiC nanopowder sintered joints. The Ti-Si-C reaction sintered joint and hybrid polymer pyrolysis/CVI bond did not show strength degradation by the irradiation. Even though the strength degradation was found in some types of joints, the apparent shear strengths were at least $80 \mathrm{MPa}$ in average.

A clear change in the fracture appearance by irradiation was observed for the Mo diffusion joints. The shear failure was observed following the irradiation, although the unirradiated joints exhibited the substrate failure. Another indication of the irradiation effect on the failure mode was observed in the SiC nanopowder slurry sintered joints. One irradiated specimen with the weakest strength (46 MPa) showed the partial joint failure like shown in Fig. 4(c). The other two specimens showed much higher strength values ( $\sim 315 \mathrm{MPa}$ ) and the substrate failure, which was similar to the unirradiated specimens. The change in the fracture mode by radiation was not observed for the other types of joints. 


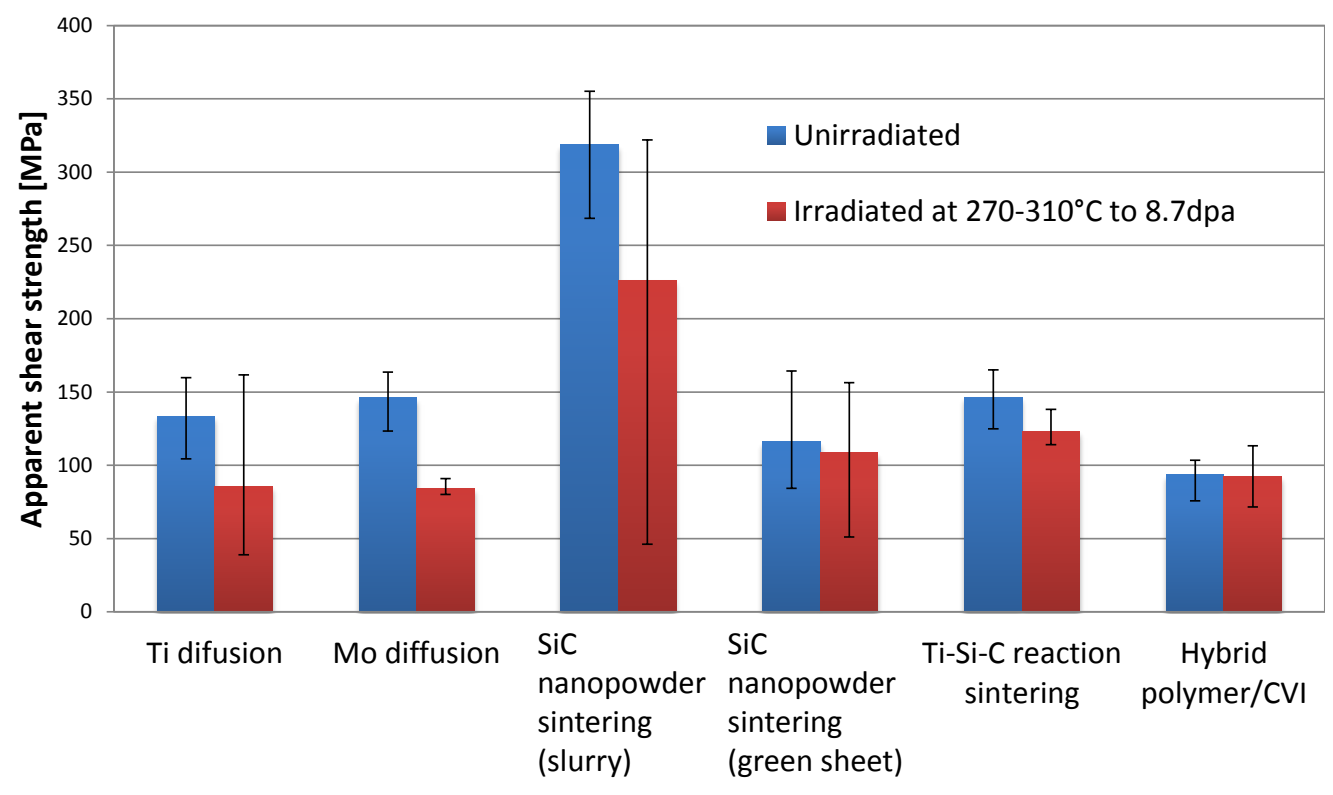

Fig. 3 Apparent torsional shear strengths of unirradiated and irradiated SiC joints. Error bars indicate one standard deviation.

Table 2 Summary of torsional shear tests of SiC joints before and after irradiation. Numbers in parentheses indicate one standard deviation. Examples of fracture appearance are shown in Fig. .

\begin{tabular}{llll}
\hline Joining Method & Condition & $\begin{array}{l}\text { Apparent Shear } \\
\text { Strength [MPa] }\end{array}$ & $\begin{array}{l}\text { Fracture } \\
\text { Surface }\end{array}$ \\
\hline \multirow{2}{*}{ Ti foil diffusion } & Unirradiated & $133(22)$ & $\mathrm{S}^{1}$ \\
& $280-310^{\circ} \mathrm{C} / 8.7 \mathrm{dpa}$ & $86(66)$ & $\mathrm{S}$ \\
\multirow{3}{*}{ Mo foil diffusion } & Unirradiated & $146(14)$ & $\mathrm{S}$ \\
\multirow{2}{*}{ SiC nanophase slurry } & Unirradiated & $320(31)$ & $\mathrm{S}$ \\
sintering & $280^{\circ} \mathrm{C} / 8.7 \mathrm{dpa}$ & $226(156)$ & $\mathrm{S}, \mathrm{P}^{3}$ \\
SiC nanophase green & Unirradiated & $116(24)$ & $\mathrm{S}, \mathrm{P}$ \\
sheet sintering & $280^{\circ} \mathrm{C} / 8.7 \mathrm{dpa}$ & $109(54)$ & $\mathrm{S}, \mathrm{P}$ \\
Ti-Si-C reaction & Unirradiated & $147(12)$ & $\mathrm{S}$ \\
sintering & $290^{\circ} \mathrm{C} / 8.7 \mathrm{dpa}$ & $123(13)$ & $\mathrm{S}$ \\
\multirow{2}{*}{ Hybrid polymer/CVI } & Unirradiated & $93(12)$ & $\mathrm{J}$ \\
& $270^{\circ} \mathrm{C} / 8.7 \mathrm{dpa}$ & $93(17)$ & $\mathrm{J}$ \\
\hline
\end{tabular}

1 Substrate

2 Joint plane

3 Substrate and joint plane 

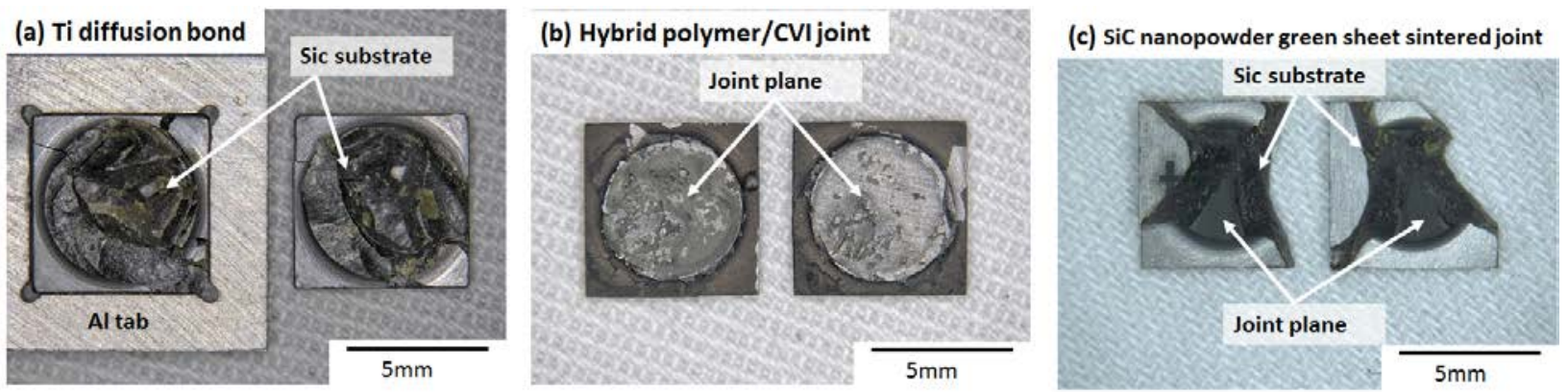

Fig. 4 Examples of fracture surfaces of torsion tested joints: (a) failure at substrate and (b) failure at joint plane, and (c) failure at both substrate and joint plane.

\subsection{Effects of irradiation on microstructural of SiC joints}

\subsubsection{Ti diffusion bond}

The phases in the Ti diffusion joint were identified by EBSD analysis on the cross section of a joint specimen as shown in Fig. 5. The bonding layer consisted of the layered structure of $\mathrm{Ti}_{3} \mathrm{SiC}_{2}$ adjacent to the $\mathrm{SiC}$ substrates and $\mathrm{TiSi}_{2}$ at the middle of the bonding layer. The joint thickness was approximately 50 $\mu \mathrm{m}$. No strong texture was observed for the $\mathrm{Ti}_{3} \mathrm{SiC}_{2}$ phase, and the $\mathrm{TiSi}_{2}$ phase had a continuous single grain (Fig. 5(b)). Both $\mathrm{Ti}_{3} \mathrm{SiC}_{2}$ and $\mathrm{TiSi}_{2}$ were also detected following the irradiation, but the quality of the mapping was degraded. TiC phase was rarely detected in the irradiated material in this study, although $\mathrm{TiC}$ was reported to be formed from $\mathrm{Ti}_{3} \mathrm{SiC}_{2}$ by a radiation enhanced dissociation [8]. The backscattered electron images of the joint before and after irradiation are shown in Fig. 6. The as-fabricated bonding layer contained micro cracks likely produced mismatch of the coefficient of thermal expansion (CTE) between the bonding layer and SiC. The irradiation clearly increased the cracks, which mostly propagated vertical to the joint interface. The cracks appeared to start from or end at the SiC substrate. Nature of the crack (intergranular or intragranular) was not identified in this study due to the poor quality of the EBSD signal of $\mathrm{Ti}_{3} \mathrm{SiC}_{2}$ phase. The degradation of the EBSD phase map especially for the $\mathrm{Ti}_{3} \mathrm{SiC}_{2}$ is expected to be due to lattice distortion by irradiation damage because the preparation of the specimen surface for the EBSD analysis was similar between the unirradiated and irradiated specimens. 

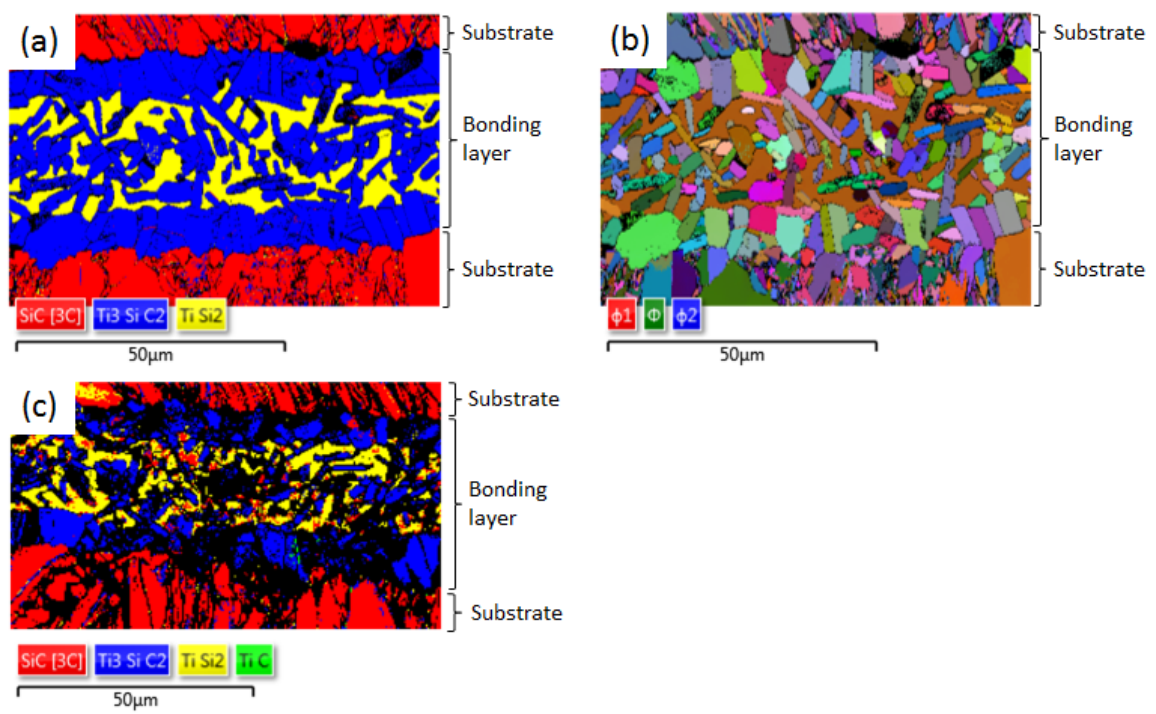

Fig. 5 EBSD analysis of Ti diffusion bond (a) phase map of unirradiated joint, (b) Euler color maps of unirradiated joint, and (c) phase map of irradiated joint.

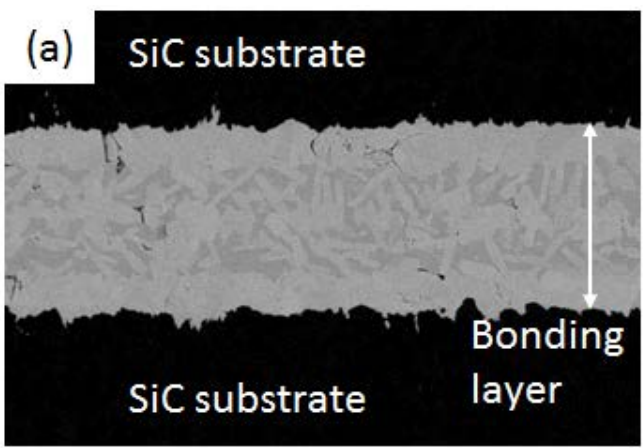

$20 \mu \mathrm{m}$

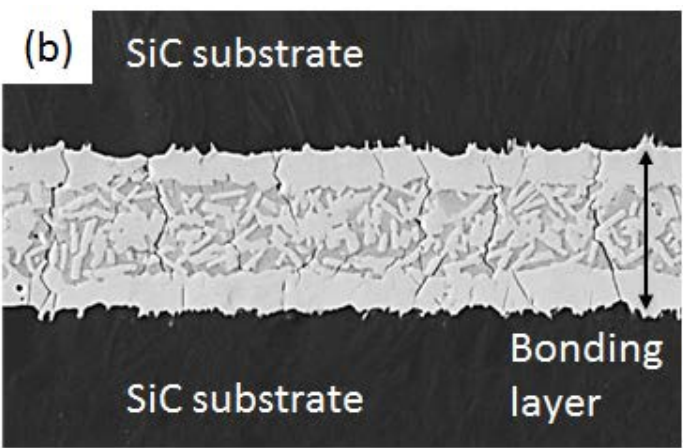

$20 \mu \mathrm{m}$

Fig. 6 Backscattered electron micrographs of Ti diffusion bond: (a) unirradiated and (b) irradiated.

The irradiation-induced cracking in the Ti diffusion bond is one of the causes of the apparent strength degradation of the joint (Fig. 3). The significant cracking is expected to cause reduction of the modulus of the bonding layer and consequently reduce the torsional shear strength according to the modeling study by Henager et al. [9]. They found that the relative applied stress on the bonding layer compared to the substrate in torsion increases with decreasing modulus of the bonding layer based on the fine element analysis. The degradation of the strength of the bonding layer itself due to the cracking may also affect the apparent torsional shear strength. Although other factors affecting the torsional strength, such as 
residual stress, cannot be clearly discussed due to the difficulty to characterize, the significance of the radiation induced cracking is an explanation of the strength degradation mechanism. The cracking was likely attributed to the differential swelling between $\mathrm{SiC}$ and the bonding layer, which was also discussed in the previous work on the irradiation effects on the SiC joints [4]. The larger swelling of the SiC substrate compared with the bonding layer can explain the vertical cracks in the bonding layer. The linear swelling of $\mathrm{SiC}$ at $300^{\circ} \mathrm{C}$ to more than $\sim 0.1$ dpa was reported to be $\sim 0.5 \%$ [5]. On the other hand, the lattice swelling of $\mathrm{Ti}_{3} \mathrm{SiC}_{2}$ was reported to be $-0.1 \%$ for a-axis and $0.8-0.9 \%$ for c-axis at $300^{\circ} \mathrm{C}$ to $\sim 0.4$ dpa-SiC. Another possibility for the cause of cracking is anisotropic swelling of the $\mathrm{Ti}_{3} \mathrm{SiC}_{2}$ grains. Since those grains had the relatively random orientation, the differential swelling along to a- and c-axes can cause the cracking. This phenomenon was also reported in $\mathrm{Ti}_{3} \mathrm{AlC}_{2}-\mathrm{Ti}_{5} \mathrm{Al}_{2} \mathrm{C}_{3}$ material [10]. However, this cannot explain the "vertical" cracks, indicating that the differential swelling between the bonding layer and substrate was dominant.

In summary, the strength degradation by the irradiation was indicated for the Ti diffusion bond. The substantial irradiation-induced cracking will cause an issue in the LWR cladding application because of the expected loss of leak tightness at the joint section.

\subsubsection{Mo diffusion bond}

The bonding layer of the unirradiated Mo diffusion joint consisted of the layered structure of $\mathrm{Mo}_{<5} \mathrm{Si}_{3} \mathrm{C}_{<1}$ adjacent to the substrate and $\mathrm{Mo}_{2} \mathrm{C}$ at the center of the joint layer (Fig. 7(a, b)). The phases were identified using SEM EDS and x-ray diffraction. The phases were similar to those reported in the previous work [11]. The pre-existing defects in unirradiated condition were cracks vertical to the joint interface, which is believed to be produced by mismatch of CTEs between the SiC substrate and Mo based phases during fabrication [11]. This CTE mismatch is known to be moderate comparing to the Ti diffusion bond [11]. The irradiation significantly introduced cracks in the bonding layer, which is similar phenomenon observed in the Ti diffusion bond. As discussed previously, a possible mechanism of the radiation-induced vertical cracks is a differential swelling between the SiC substrate and joint phases, though the swelling behaviors of the $\mathrm{Mo}_{<5} \mathrm{Si}_{3} \mathrm{C}_{<1}$ and $\mathrm{Mo}_{2} \mathrm{C}$ are unknown. In contrast to the Ti diffusion bond, the cracks in the Mo diffusion bond formed networks as shown in Fig. 7(d). This result indicates significant damage of the bonding layer and can explain the obvious strength degradation of the Mo diffusion bond after irradiation (Fig. 3). The irradiation-induced change in the fracture behavior during the torsion test from the substrate failure to the joint failure can be also explained by this network 
cracking. As such significant joint degradation, the Mo diffusion bond investigated will not be useful for the end-plug application.
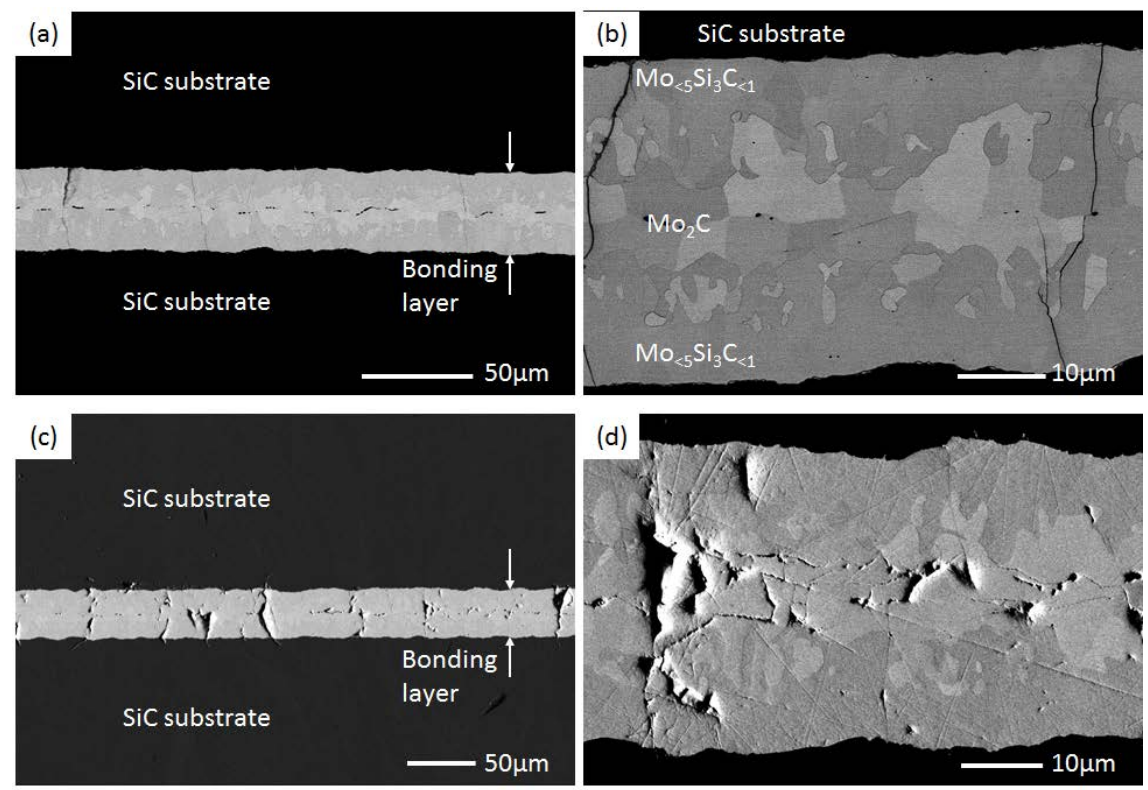

Fig. 7 Backscattered electron images of Mo diffusion bond: (a, b) unirradiated and (c, d) irradiated.

\subsubsection{SiC nanopowder sintered joint}

Method of sintering SiC nanopowder with oxide additives formed a SiC based bonding layer with secondary phases. Cross-sectional backscattered electron micrographs of two types of the SiC nanopowder sintered joints before the irradiation are shown in Fig. 8 (a, c, d). The joint thickness was $~ 80$ and $150 \mu \mathrm{m}$ for the $\mathrm{SiC}$ joints formed using slurry and green sheet, respectively. The joint layer appears to be highly dense for the slurry joint. In addition, the secondary phases attributed to the oxide additives were well dispersed, and up to $\sim 5 \mu \mathrm{m}$-sized segregation of $\mathrm{Y}$-Al oxide phase was observed. The microstructure of the green sheet joint is clearly different from the slurry joint. The green sheet joint was partially deboned due to the presence of large $(\sim 50$ to $\sim 100 \mu \mathrm{m})$ pores $($ Fig. 8(c)). In addition, linear segregation of the secondary phases was observed in the bonding layer (Fig. 8(d)). Those results show that the microstructure of the green sheet joint was not uniform. The SEM-EDS mapping (Fig. 9) reveals that the secondary phases consists of aluminum, yttrium, and zirconium oxides in as-fabricated condition. The detection of the substantial amount of zirconium in the oxide phases was unexpected since the sintering additives used were only alumina and yttria. The zirconium contamination likely came from the 
media of the ball milling during the processing. The EDS analysis estimated the inclusion of $\mathrm{Zr}$ in the bonding layer was $\sim 5$ wt.\%. The SEM observation following the irradiation (Fig. 8(a, e)) did not show any obvious microstructural changes; irradiation induced cracking potentially caused by differential swelling of the bonding layer and substrate was not found. Since swelling of nanopowder sintered $\mathrm{SiC}$ with Y-Al oxides was similar to CVD SiC at $\sim 300^{\circ} \mathrm{C}$ [12], the result is not surprising.
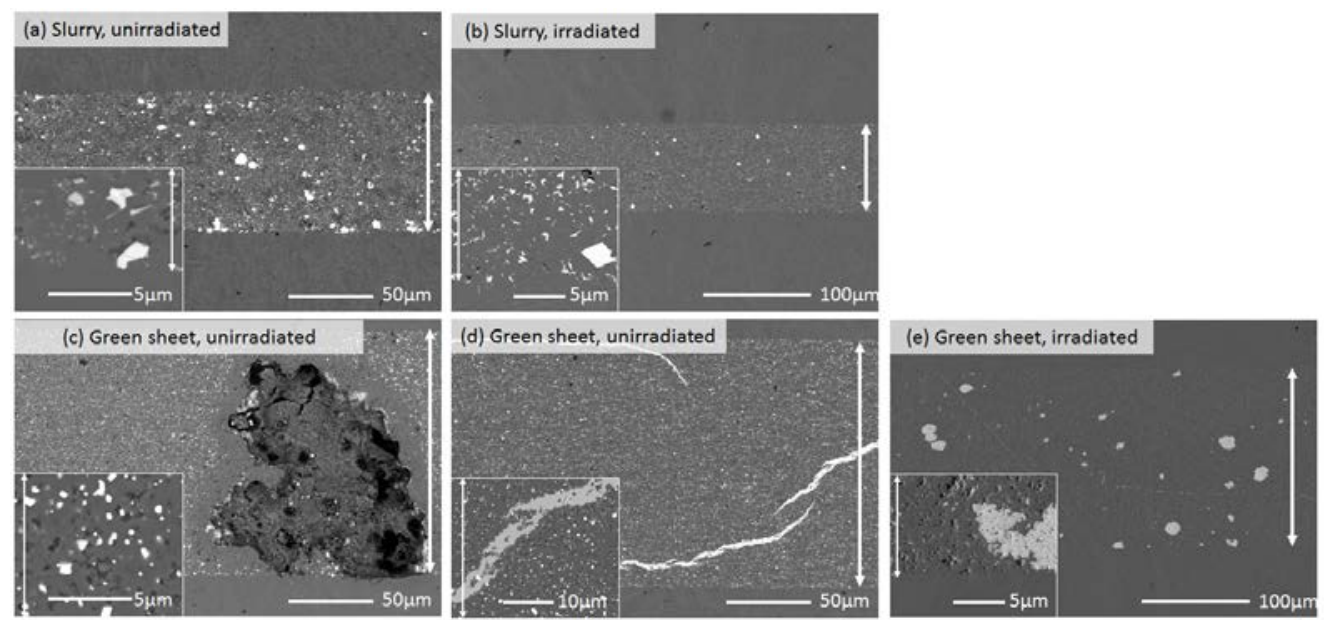

Fig. 8 Cross sectional backscattered electron micrographs of SiC nanopowder sintered joints: (a) slurry method, unirradiated, (b) slurry method, irradiated, (c,d) green sheet method, unirradiated, and (e) green sheet method, irradiated. Bonding layer is indicated by arrow.

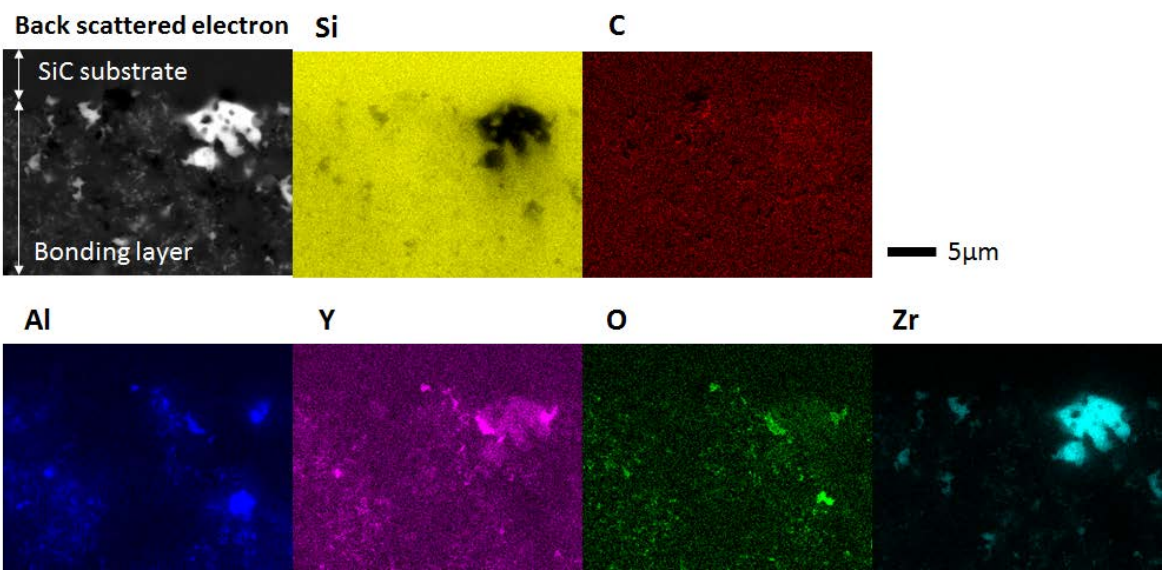

Fig. 9 SEM-EDS elemental maps of unirradiated SiC nanopowder sintered joint formed using slurry. 
The torsional shear test demonstrated the slurry joint was much stronger than the green sheet joint (Fig. 3). This result is reasonable because the green sheet joint contained substantial defects such as the pores and oxide phase segregation. The differential fracture behavior of the torsion specimens: substrate failure for the slurry joint and partial joint failure for the green sheet joint, can be also explained by the presence of these defects. A discussion point is a cause of large strength deviations for both types of the SiC joints following the irradiation. A possibility is non-uniformity of the microstructure of the joints among the test specimens. The torsional tests and record of the specimen machining found that the relatively weak joint specimens were taken from the particular part of the original bonded plates such as near edge of the plates. Since the strength deviation of the unirradiated joint was moderate, the strength of the irradiated $\mathrm{SiC}$ nanopowder sintered joints is suspected to be more sensitive to the microstructure due to possible poor irradiation resistance of the secondary phases [13]. Since some joints did not show strength degradation by the radiation and no obvious microstructural change in the bonding layer was observed, the SiC nanopowder sintered joints is potentially useful for the LWR clad application when the microstructure is well controlled.

\subsubsection{Ti-Si-C based reaction sintered joint}

Cross-sectional backscattered electron images of the Ti-Si-C based reaction sintered joint are shown in Fig. 11(a,b). The joint layer appears to be dense, and the joint thickness is about $150 \mu \mathrm{m}$. The dominant processing defect in the joint layer is a crack roughly perpendicular to the joint boundary. The bonding phases in the unirradiated material were identified using EBSD technique as shown in Fig. 12. The bonded zone consisted of SiC grains and Ti-Si-C phases. The phase mapping shows that the bonding layer consists of $43 \mathrm{vol} \%$ of $\mathrm{Ti}_{3} \mathrm{SiC}_{2}, 42 \mathrm{vol} \%$ of SiC phases (mainly $6 \mathrm{H}$ or $4 \mathrm{H} \mathrm{SiC}$ ), and $15 \mathrm{vol} . \%$ of TiC. The Euler color map reveals that there is no strong grain texture in both the SiC substrate and the joint phases.

The irradiation induced significant amount of micro cracks as shown in Fig. 11(c). Those cracks were formed within the $\mathrm{Ti}_{3} \mathrm{SiC}_{2}$ and $\mathrm{TiC}$ phases. The overall crack path could not be identified due to the poor quality of the EBSD signal from, which was same phenomenon observed in the Ti diffusion bond. Only specific cracks were characterized using EBSD as follows. The irradiation-induced cracks within a relatively large $\mathrm{Ti}_{3} \mathrm{SiC}_{2}$ grain were analyzed as shown in Fig. 13. The band contrast image shows three cracks propagating to same direction. Considering the crystallographic orientation, the crack was nearly parallel to the c-axis of $\mathrm{Ti}_{3} \mathrm{SiC}_{2}$. Since c-axis and a-axis of $\mathrm{Ti}_{3} \mathrm{SiC}_{2}$ expands and slightly shrinks, respectively [8] and surrounding SiC grains swells, the differential swelling can generate tensile residual 
stress within the basal plane and consequently introduce the cracks along c-axis of $\mathrm{Ti}_{3} \mathrm{SiC}_{2}$ phase. The differential swelling reasonably explains the irradiation-induced cracking mainly observed in $\mathrm{Ti}_{3} \mathrm{SiC}_{2}$ phases. Note that the grain boundary cracking was also possible due to the anisotropic swelling of $\mathrm{Ti}_{3} \mathrm{SiC}_{2}$ with random grain orientations, which was not clearly detected in this study due to the difficulty of the analysis.

Although the strength of the joint was retained following the irradiation, the micro-cracking will be an issue for the LWR clad application because of expected loss of leak tightness of the joint. The strength retention of this type of joint with micro cracking was also observed in previous work [4]. The reduction of the mechanical properties of the bonding layer is not expected to be catastrophic.
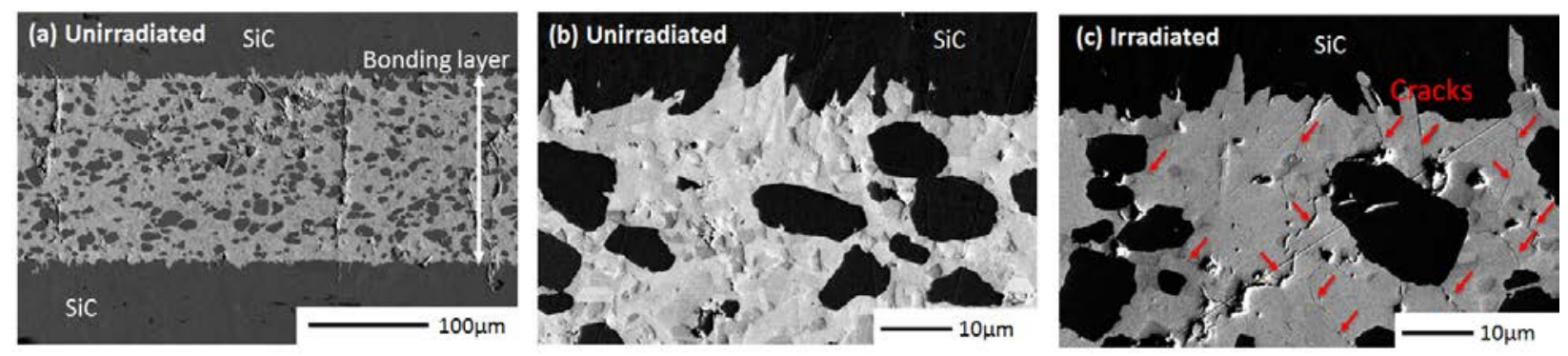

Fig. 11 Cross-sectional backscattered electron micrographs of Ti-Si-C based reaction sintered joint: (a, b) unirradiated, and (c) irradiated.

(a)

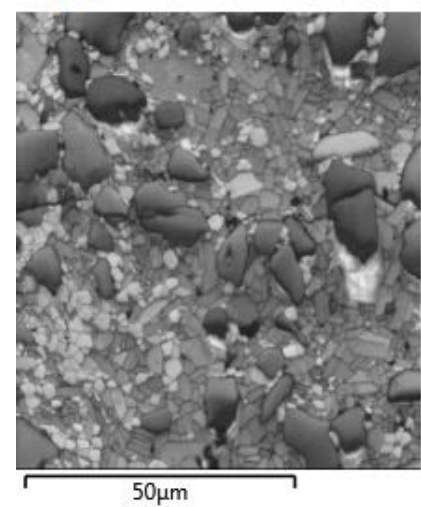

(b)

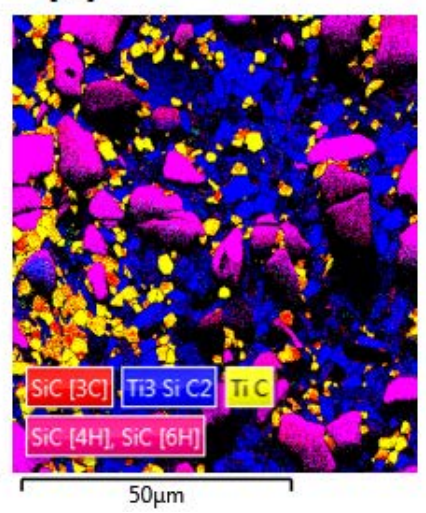

(c)

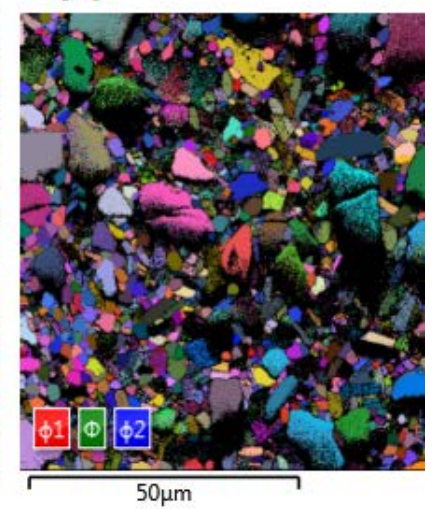

Fig. 12 EBSD analysis of bonding layer of unirradiated Ti-Si-C based reaction sintered SiC joint: (a) band contrast image, (b) phase map, and (c) Euler color map. 


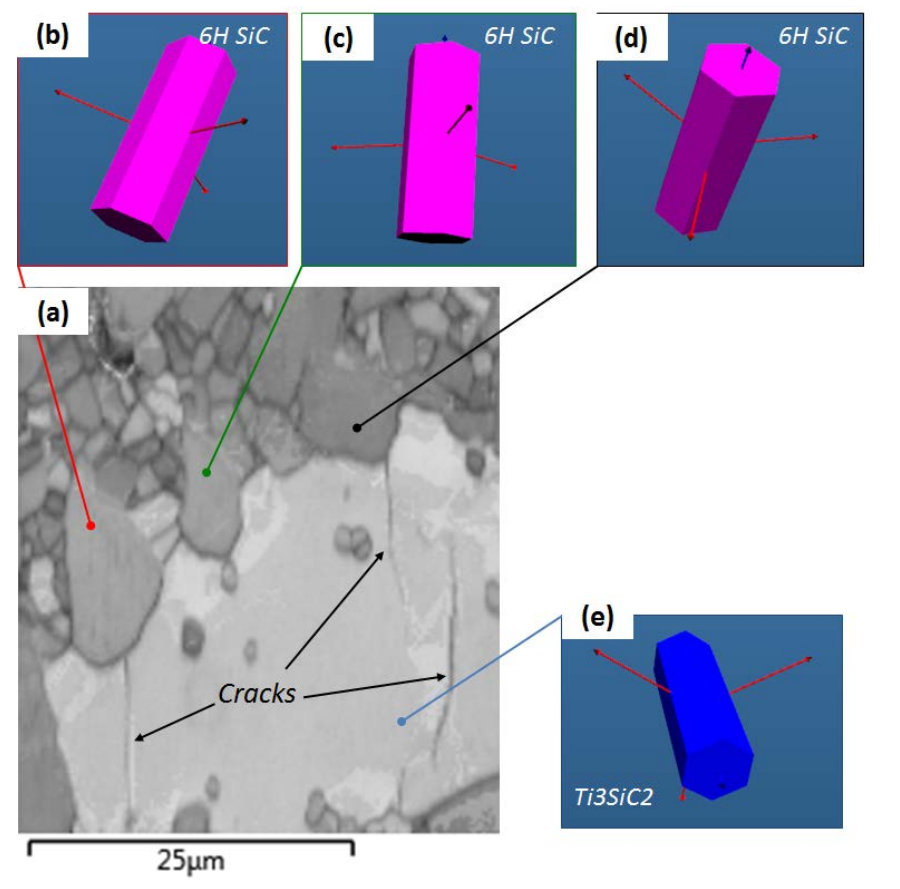

Fig. 13 EBSD analysis of irradiated Ti-Si-C based reaction sintered SiC joint: (a) band contrast image, (b, c, d) surface normal crystallographic orientation of $6 \mathrm{H} \mathrm{SiC} \mathrm{grains,} \mathrm{and} \mathrm{(c)} \mathrm{surface} \mathrm{normal} \mathrm{crystallographic}$ orientation of $\mathrm{Ti}_{3} \mathrm{SiC}_{2}$ grain. Figs (b,c,d,e) show schematic unit cell of hexagonal structure.

\subsubsection{Hybrid polymer pyrolysis/CVI joint}

Both polymer pyrolysis and CVI joining method provided pure SiC bonding layers. The cross-section secondary electron micrograph of the unirraidated torsion specimen shows the porous polymer bonding layer between the SiC substrates and on the side surfaces of the substrates and dense CVI SiC phase on the polymer joint phases, as shown in Fig. 14(a, b). The CVI SiC phase was partially connected with the SiC substrates. The joint microstructure was not obviously changed by the irradiation: no indication of damage such as micro crack was observed (Fig. 14(c, d)). This result is consistent with the retention of the torsional shear strength (Fig. 3). The bonding phases in the unirradiated joint were evaluated by EBSD (Fig. 15). The band contrast image, phase map, and Euler color map revealed that the phases of the polymer joint consisted of mainly beta (3C) SiC grains with a few micron sizes and random orientations. The unidentified area in the phase map indicates the porous region. On the other hand, the phases in the CVI joint appeared to be mixture of beta and alpha $(6 \mathrm{H}$ and $4 \mathrm{H}) \mathrm{SiC}$. The grain size was very fine (submicron). In addition, large fraction of the phases was not identified, even though the CVI layer was dense (Fig. 14(b)). This may be caused by the grain size smaller than the resolution limit ( 100nm) or amorphous-like SiC phases. 
Although alpha $\mathrm{SiC}$ phases have anisotropic lattice structures, cracking due to the anisotropic swelling was not observed. Snead et al. recently revealed isotropic lattice expansion of single crystal alpha SiC irradiated at $\sim 60^{\circ} \mathrm{C}$ [14], which is consistent with our observation though the irradiation temperature was different. The important finding is that the differential swelling did not appear to be an issue for this type of joint. Proven irradiation tolerance of SiC [5] in the bonding layer is the reason of maintaining the joint strength and the excellent microstructural stability of this joint.
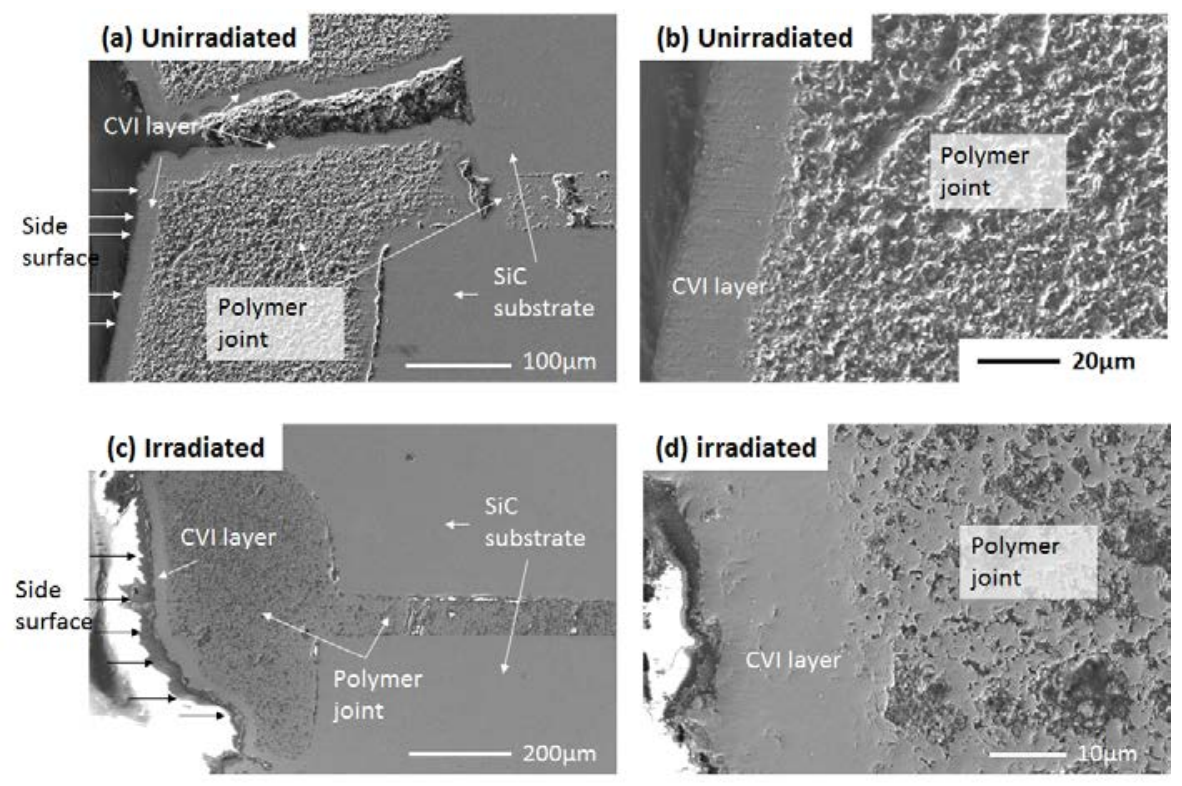

Fig. 14 Secondary electron micrographs of hybrid polymer/CVI joint: (a, b) unirradiated, and (c, d) irradiated. Cross-section of hourglass torsion specimen near neck section was observed.

(a)

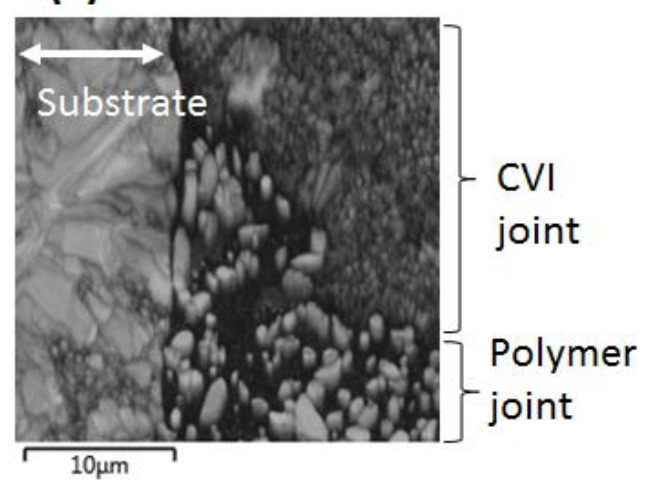

(b)

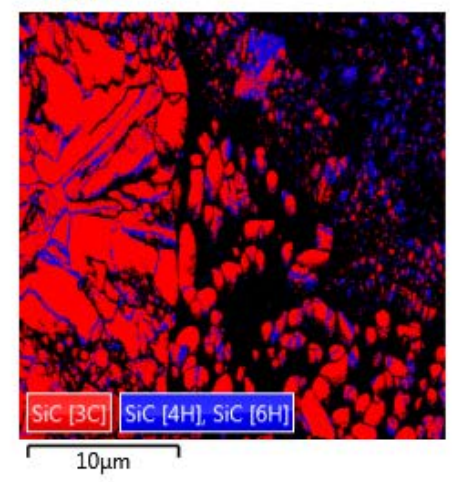

(c)

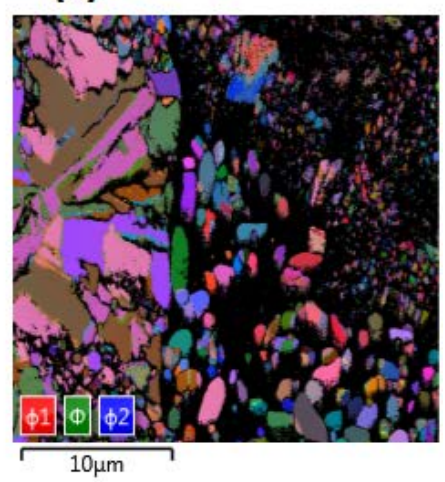

Fig. 15 EBSD analysis of unirradiated hybrid polymer/CVI SiC joint: (a) band contrast image, (b) phase map, and (c) Euler color map. 


\section{Conclusions}

Irradiation resistance of candidate $\mathrm{SiC}$ joints for LWR cladding application was investigated by neutron irradiation at $\sim 300^{\circ} \mathrm{C}$ to $8.7 \mathrm{dpa}-\mathrm{SiC}$ followed by torsional shear test and microstructural observation. The findings are as follows.

- The Ti diffusion bond with $\mathrm{Ti}_{3} \mathrm{SiC}_{2}$ and $\mathrm{TiSi}_{2}$ joint phases degraded by the irradiation. The joint strength appeared to be lowered, and irradiation-induced cracking was found.

- The Mo diffusion bond with the bonding phases of $\mathrm{Mo}_{<5} \mathrm{Si}_{3} \mathrm{C}_{<1}$ and $\mathrm{Mo}_{2} \mathrm{C}$ was also degraded by the irradiation. The joint strengths clearly decreased, and irradiation induced network cracking.

- The SiC nanopowder sintered joints using slurry or green sheet consisted of bonding layer of SiC grains and secondary phases of Y-Al-Zr oxides. Although deviation of the irradiated strength was large, these joints exhibited excellent microstructural stabilities.

- The Ti-Si-C based reaction sintering method provided the bonding layer of $\mathrm{Ti}_{3} \mathrm{SiC}_{2}$ and $\mathrm{SiC}$. The joint retained the strength, but the irradiation-induced micro-cracking was significant.

- The hybrid polymer pyrolysis/CVI method formed SiC bonding layers. The joint retained the strength and showed stable microstructure following the irradiation.

- In case that the majority of the bonding layer was non-SiC phase, the differential swelling between the joint phases and SiC substrates likely caused the cracking. On the other hand, SiC based bonding layer did not have the differential swelling issue, even though the secondary phases were present or both cubic and hexagonal SiC phases existed.

\section{Acknowledgments}

This work was sponsored by the U.S. Department of Energy, Office of Nuclear Energy, for the Fuel Cycle Research \& Development program under contact DE-AC05-00OR22725 with Oak Ridge National Laboratories managed by UT-Battelle, LLC. Research was supported in part by High Flux Isotope Reactor, which is sponsored by the Office of Basic Energy Sciences, U.S. Department of Energy. 


\section{References}

[1] Y. Katoh, L.L. Snead, C.H. Henager, T. Nozawa, T. Hinoki, A. Iveković, S. Novak, S.G. de Vicente, Current status and recent research achievements in $\mathrm{SiC} / \mathrm{SiC}$ composites, Journal of Nuclear Materials 455(1) (2014) 387-397.

[2] S.J. Zinkle, K.A. Terrani, J.C. Gehin, L.J. Ott, L.L. Snead, Accident tolerant fuels for LWRs: A perspective, Journal of Nuclear Materials 448(1) (2014) 374-379.

[3] Y. Katoh, K.A. Terrani, Systematic Technology Evaluation Program for SiC/SiC Composite-based Accident-Tolerant LWR Fuel Cladding and Core Structures: Revision 2015, Oak Ridge National Laboratory (ORNL), 2015.

[4] Y. Katoh, L.L. Snead, T. Cheng, C. Shih, W.D. Lewis, T. Koyanagi, T. Hinoki, C.H. Henager, M. Ferraris, Radiation-tolerant joining technologies for silicon carbide ceramics and composites, Journal of Nuclear Materials 448(1) (2014) 497-511.

[5] L.L. Snead, T. Nozawa, Y. Katoh, T.-S. Byun, S. Kondo, D.A. Petti, Handbook of SiC properties for fuel performance modeling, Journal of nuclear materials 371(1) (2007) 329-377.

[6] A.A. Campbell, W.D. Porter, Y. Katoh, L.L. Snead, Method for analyzing passive silicon carbide thermometry with a continuous dilatometer to determine irradiation temperature, Nuclear Instruments and Methods in Physics Research Section B: Beam Interactions with Materials and Atoms 370 (2016) 49-58. [7] H.E. Khalifa, C.P. Deck, C.A. Back, High durability joints between ceramic articles, and methods of making and using same, Google Patents, 2015.

[8] D.J. Tallman, E.N. Hoffman, N.C. El'ad, B.L. Garcia-Diaz, G. Kohse, R.L. Sindelar, M.W. Barsoum, Effect of neutron irradiation on select MAX phases, Acta Materialia 85 (2015) 132-143.

[9] C.H. Henager, B.N. Nguyen, R.J. Kurtz, T.J. Roosendaal, B.A. Borlaug, M. Ferraris, A. Ventrella, Y. Katoh, Modeling and testing miniature torsion specimens for SiC joining development studies for fusion, Journal of Nuclear Materials 466 (2015) 253-268.

[10] C. Ang, C. Silva, C. Shih, T. Koyanagi, Y. Katoh, S.J. Zinkle, Anisotropic swelling and microcracking of neutron irradiated Ti 3 AlC 2-Ti 5 Al 2 C 3 materials, Scripta Materialia 114 (2016) 7478.

[11] B. Cockeram, The diffusion bonding of silicon carbide and boron carbide using refractory metals, Bettis Atomic Power Lab., West Mifflin, PA (US), 1999.

[12] L. Snead, K. Terrani, Y. Katoh, C. Silva, K. Leonard, A. Perez-Bergquist, Stability of SiC-matrix microencapsulated fuel constituents at relevant LWR conditions, Journal of Nuclear Materials 448(1) (2014) 389-398.

[13] T. Koyanagi, S. Kondo, T. Hinoki, The influence of sintering additives on the irradiation resistance of NITE SiC, Journal of Nuclear Materials 417(1) (2011) 435-439.

[14] L.L. Snead, Y. Katoh, T. Koyanagi, K. Terrani, E.D. Specht, Dimensional Isotropy of 6H and 3C SiC Under Neutron Irradiation, Journal of Nuclear Materials (2016). 